University of Rhode Island

DigitalCommons@URI

Open Access Dissertations

2002

\title{
Adult Attachment Patterns: The Relationship Between Security of Attachment and Adjustment to Prison and Separation From Loved Ones
}

Steven Kenneth Diehl

University of Rhode Island

Follow this and additional works at: https://digitalcommons.uri.edu/oa_diss

\section{Recommended Citation}

Diehl, Steven Kenneth, "Adult Attachment Patterns: The Relationship Between Security of Attachment and Adjustment to Prison and Separation From Loved Ones" (2002). Open Access Dissertations. Paper 1059. https://digitalcommons.uri.edu/oa_diss/1059

This Dissertation is brought to you for free and open access by DigitalCommons@URI. It has been accepted for inclusion in Open Access Dissertations by an authorized administrator of DigitalCommons@URI. For more information, please contact digitalcommons-group@uri.edu. 
ADULT ATTACHMENT PATTERNS: THE RELATIONSHIP $\quad \begin{aligned} & \text { A } 86 \\ & 954\end{aligned}$ BETWEEN SECURITY OF ATTACHMENT AND ADJUSTMENT TO PRISON AND SEPARATION FROM LOVED ONES

BY

STEVEN KENNETH DIEHL

A DISSERTATION IN PARTIAL FULFILLMENT OF THE

REQUIREMENTS FOR THE DEGREE OF

DOCTOR OF PHILOSOPHY

IN

PSYCHOLOGY

UNIVERSITY OF RHODE ISLAND 
This study was designed primarily to begin to bridge the gap that currently exists between the adult attachment literature and the initial studies of attachment among infants discussed by John Bowlby and Mary Ainsworth by exploring a real world, present time disruption of attachment relationships among adult inmates. Infant attachment research focused on emotional and behavioral reactions to separation from attachment figures and this study's main premise was to examine adult reactions to being separated from loved ones. Subjects consisted of 167 male inmates who had been sentenced to at least a six month term of incarceration at a state penitentiary. Inmates were tested within the first month of their imprisonment to assess acute emotional and behavioral reactions to being separated from loved ones and were administered the Relationship Questionnaire (Bartholomew \& Horowitz, 1991) which utilizes a four-category model of adult attachment to assess individual attachment patterns. It was predicted that Secure and Dismissing inmates would adjust better both behaviorally and emotionally to separation from loved ones than either Fearful or Preoccupied inmates. Emotional adjustment was measured via scores on specific scales of the MMPI-2, the Brief Symptom Inventory, and a mental status interview and behavioral adjustment was measured by reviewing the number and severity of inmates' disciplinary records.

Overall, the analyses lent partial support to the hypotheses. There was some consistency across the objective measures of emotional adjustment in that Secure and Dismissing inmates had BSI and MMPI-2 scores indicative of better adjustment to separation from loved ones than Fearful and Preoccupied inmates, particularly on the depression and anxiety scales. The results from the mental status interview were less 
clear. Additionally, the attachment groups did not differ from each other on the behavioral indicators of adjustment. The results are discussed in terms of connecting the infant and adult attachment literatures as well as their contribution to current adult attachment research. Additionally, implications for mental health professionals working both inside and outside of prison settings are discussed. Limitations of the study and suggestions for future research are also highlighted. 


\section{Acknowledgment}

First and foremost, I would like to thank my family and friends for their love, caring, and support. I would like to dedicate this dissertation to my parents both of whom have shown and given me all the love in the world. Without them I am nothing. And, yes, I'm finally done! I would also like to thank my brother Tim and sister Dani: I wish completing this project hadn't "separated" me from you both for so long. I love you both. I would also like to thank two people particularly who have made my life meaningful and fun and wonderful - you two are my stars forever shining...thanks so much Bailey and Leah-Anne. I love you guys. Finally, I have a ton of people I am thankful to have in my life and who have given me so much. Without these folks, I wouldn't be me and this project would never have been completed. To name a few (but don't be mad if aren't listed here, you are in my heart), thanks Ryan, Shunney, Melissa, Dana, Maria, Derek, Melinda, Keith, and Jean-Paul. I can't put into words how each of you in your own way have made me feel special and inspired me in my life. I can't always be near you, but your light and warmth radiates no matter where I am. God bless everyone I've mentioned and all the others... you know who you are....

I have many people to thank for their support through the psychology graduate program at URI and for their participation in my growth as a psychologist. Thank you Henry Biller for being the most supportive major professor I could have imagined. Thank you Peter Merenda and Gwenneth Rae for being helpful, thoughtful, and supportive members of my committee over the years. Thanks also to Maria Garrido, a mentor and a colleague who contributed significantly to my development as a psychologist. Finally, I would like to thank Jerry Schaffran, Ann Varna-Garis, Mary 
McNiff, Jean Maher, and Patricia Morokoff for their support and assistance during my time at the University of Rhode Island.

Everyone listed on this page, this dissertation is an extension of you... 


\section{Preface}

The dissertation is organized into five main parts. First, the introduction section includes a statement of the problem studied, the justification and significance of the study, a review of the relevant attachment and prison adjustment literature, and the research questions and hypotheses of the study. Second, the method section includes a description of the setting, subjects, sampling procedure, measures and assessment devices, procedure, methods of data analysis, and the resources that were required for the study. Third, the results section reviews the data analyses and relevant findings. Fourth, the discussion section reviews the predictions of the study and includes an interpretation of the results, clinical and research implications of the study, as well as limitations and future research directions. The fifth and final section includes references cited in the study as well as relevant appendices and tables. 
PREFACE

INTRODUCTION

Statement of Problem

Justification for and Significance of the Study

Attachment Theory

Adult Attachment

Attachment, Separation, and Responses to Distress

Prison Adjustment and Adaptation

Attachment and Prison Adjustment

Research Question and Hypothesis

METHOD

Setting

Subjects

Sampling Procedures and Calendar of Events

Measures

Attachment Measures

Measures of Emotional Adjustment to Prison

Brief Symptom Inventory

Minnesota Multiphasic Personality Inventory - 2 57

Brief Mental/Affective Status Interview $\quad 60$

Measure of Behavioral Adjustment $\quad 62$

$\begin{array}{ll}\text { Procedure } & 64\end{array}$

Method of Data Analysis $\quad 67$

Resources Required $\quad 69$

RESULTS $\quad 71$

Tests of Main Hypotheses - Analysis of Variance $\quad 71$

Exploratory Multiple Discriminant Function Analyses $\quad 78$

DISCUSSION

$\begin{array}{ll}\text { Review of Predictions } & 84\end{array}$

Emotional Adjustment $\quad 84$

$\begin{array}{lr}\text { Behavioral Adjustment } & 92\end{array}$

$\begin{array}{lr}\text { Implications } & 94\end{array}$

Attachment Theory Among Infants and Adults 94

Adult Attachment Research $\quad 98$

Prison Adjustment Research and Application $\quad 100$

Clinical and Counseling Implications $\quad 102$

$\begin{array}{ll}\text { Limitations of the Study } & 107\end{array}$ 
APPENDIX A-Relationship Questionnaire

APPENDIX B-Mental/Affective Status Interview

TABLES 
Tables

Table 1 Results for One-Way ANOVAs for the MMPI-2 Scales 118

Table 2 Results for One-Way ANOVAs for the BSI Scales $\quad 119$

Table 3 Results for One-Way ANOVAs for the Mental Status

Interview and Disciplinary Violations

Table 4 Multiple Discriminant Function Analysis for the MMPI-2 Scales and the Disciplinary Variables

Table 5 Group Centroids for the First Discriminant Analysis

Table 6 Multiple Discriminant Function Analysis for the BSI Scales and the Disciplinary Variables

Table 7 Group Centroids for the Second Discriminant Analysis 124 


\section{Introduction}

\section{Statement of the Problem}

Attachment theory, whether applied to infants, children, or adults, focuses on the development and maintenance of significant familial and interpersonal relationships. A core concept of attachment theory is that within humans, attachment is a behavioral control system that directs and organizes behavior and allows one to achieve evolutionary adaptive goals (West \& Sheldon-Keller, 1994). Much of the research done with infants and children has been based on the assumption that separation from a primary attachment figure activates this control system in such a way that behaviors are initiated that enhance the likelihood of regaining this figure's presence (Weiss, 1982). Patterns of attachment have been identified which have been linked to the specific types of behavior likely to be engaged in by the infant during such separations (Ainsworth, Blehar, Waters, \& Wall, 1978).

Studies of adult attachment and real-life separations from significant others are scarce. Such studies have typically involved expected developmental transitions (e.g., going away to school) (Rice, FitzGerald, Whaley, \& Gibbs, 1995), have focused on situations where the attachment figure is permanently inaccessible (as in the case of death of a spouse) (Parkes, 1987; Glick, Weiss, \& Parkes, 1974), or have examined desired volitional separations as in divorce (Weiss, 1975).

One situation that involves an often unexpected, undesired separation, and where the accessibility of significant others is uncertain, is when adults are incarcerated for criminal behavior. Research has shown that the transition to a prison environment is 
often a time of emotional distress for some inmates, particularly at the onset of their sentences (Mackenzie \& Goodstein, 1985; Bonta \& Gendreau, 1990). One reason for this may be that incarcerated adults react differently to being separated from loved ones dependent upon the pattern of adult attachment they exhibit.

This study seeks to examine the possibility that patterns of attachment of incarcerated adult offenders are related to adjustment to a prison environment. In particular, it is expected that the representational models that underlie Bartholomew's (1990) four-category attachment typology will be related to emotional reactions to incarceration, as well as to rates of disciplinary infractions, during the initial phase of imprisonment. In addition to utilizing an older, more ethnically diverse population, this research will also connect the literature on patterns of adult attachment to an examination of individual reactions to a significant separation, which was the emphasis of the initial attachment research done with infants. Such a relationship could also have practical implications for the visiting policies of prison systems as well as intervention strategies for prison psychologists, and could extend the utility and validity of research into individual differences in patterns of adult attachment.

\section{Justification for and Significance of the Study}

Attachment theory has been used to describe, explain, and predict relationship processes across the life-span, from infancy through adolescence, from adulthood to death. While initially focusing on normative relationship processes, the theory has been increasingly used to describe individual differences in the ways we relate to others and how we regulate emotion during times of stress. Studies of individual differences in 
attachment began in a laboratory setting. Researchers would record the reactions of infants to periods of separation from their primary care giver as well as the behaviors emitted by these same infants upon reunion with this 'attachment figure.' Through such methods, patterns or styles of infant-mother attachment were described. These patterns of attachment differed in that some infants appeared to regulate emotional distress resulting from separation anxiety more effectively than other infants. Some infant-mother dyads appeared to be more attuned to each other's needs (securely attached), while other infantmother dyads seemed to be 'out of synch' with each other (insecurely attached).

More recently, attachment theory has been used to explain processes involved in adult romantic relationships. From its inception, research on adult attachment has almost exclusively focused on individual differences in the ways adults explain, understand, describe, and approach romantic relationships. Much of this research has relied on survey and questionnaire methods of assessing past or concurrent relationship processes of college student samples. While certainly this research has been helpful in extending the tenets of attachment theory to adult relationships, this approach is problematic for several reasons. First, the almost exclusive utilization of college age samples limits the external validity of the results. Second, group survey methods rely on subjects accurately reporting past relationships events and processes, the validity of which is questionable. Finally, research topics have tended to stray considerably from the original relationship phenomena attachment theory was developed to explain. Emotional and behavioral reactions to separation from an attachment figure have been largely ignored in the adult attachment literature. These phenomena were at the core of research into infant 
attachment patterns.

The study of the adjustment reactions of recently incarcerated adults may rectify some of these theoretical and methodological shortcomings. Studies of inmates have consistently described the first weeks and months of incarceration as being a time of considerable emotional and behavioral distress as inmates adjust to their new environment. This initial adjustment period is often characterized by depressive and anxious emotional reactions, as well as by rule-breaking and behavioral acting out. Previous studies attempted to explain their reactions in terms of age, mental disorder, offense committed, and other demographic factors. Other studies have suggested that certain personality characteristics are the cause of these adjustment difficulties. What has not been examined is individual differences in inmates' reactions to being separated from their families, friends, and loved ones, and how this separation may help to explain this initial phase of prison maladjustment. Adult attachments could be a factor in adjustment to such a separation.

The restrictive environment inherent in prison settings severely limits ones accessibility to and interactions with attachment figures. In addition, adult inmates are faced with greatly reduced autonomy and increased stress from possible perceived threats of violence from staff and other inmates. Under threatening conditions outside of a prison environment, one could turn to trusted others for comfort and support. However, incarceration limits ones ability to seek such support from attachment relationships. Emotional distress and aggressive behavior may result as one adjusts to the inaccessibility of such attachments. 
The question this study sought to examine is whether the emotional and behavioral reactions to prison adjustment vary by the security one has in his or her attachment relationships. In other words, do securely attached adults react differently to incarceration than insecurely attached adults? And among those who are insecurely attached, do certain patterns of insecure attachment associate with better or poorer adjustment reactions than other insecure patterns of attachment?

By studying prison adjustment reactions, one has access to an older, more ethnically diverse population, and one is examining a real-life unexpected, undesired separation from one's attachment relationships. This directly addresses some of the criticisms of past adult attachment research. It also extends the emphasis in the adult attachment literature to individual differences in reactions to real-life separations, an emphasis that is the basis of the initial attachment work done with infants. In addition, if the initial distressing transition reactions often observed in recently incarcerated inmates are found to be related to patterns of attachment, prison officials may have the impetus to change existing visiting policies so as to increase the accessibility of an inmate's family and other attachment figures. This could serve to ease the stress of adjustment to prison for some inmates, as well as to take some of the strain off limited prison mental health resources and reduce the number of disciplinary violations prison officials must manage.

In the following sections, the principal literature relevant to both attachment and prison adjustment has been reviewed. First, attachment theory will be described as proposed by its founder John Bowlby as well as Mary Ainsworth. Next, the adult attachment literature has been outlined, with particular attention being given to how this 
research area grew from studies of the infant-caregiver attachment system. Studies of adult attachment and its relation to separation from significant others has been reviewed. Unlike the infant attachment field, research in this area is relatively scarce. The literature relevant to prison adjustment has been described, with an emphasis placed on variables that have been shown to be related to negative adjustment outcomes. Finally, the attachment and prison adjustment literatures has been used as the basis for the hypotheses and predictions of the present study on the relationship between adult attachment patterns and adjustment to a prison environment.

\section{Attachment Theory}

Attachment theory, as described by its founder John Bowlby, originated from his observations that an infant's well-being may be negatively impacted by significant separations from its primary caregiver (Bowlby, 1958). Based upon his observations, Bowlby $(1969,1973,1980)$ outlined a theory based upon principles drawn from psychoanalysis, object relations theory, ethnology, control systems theory, and evolutionary theory which sought to explain the importance of infant-caregiver relationships in the healthy development of the infant. The resultant attachment theory has been very influential in our understanding of infant and child development and its impact on later functioning in adolescence and adulthood.

Bowlby (1969) believed that the attachment system was one of several behavioral control systems an infant possesses at birth. This attachment system's primary function is to ensure the safety and survival of the infant so as to increase its chances of later procreation upon maturity. The set goal of the attachment behavioral system is to 
maintain proximity to the primary caregiver. The closer the infant is to its caregiver, the less danger there is of predation. The attachment system serves to maintain proximity to the caregiver as the child interacts, explores, and learns about its environment. However, separations from the primary caregiver, whether real or imagined, are perceived as threatening to the infant such that attachment behaviors (e.g., crying, reaching, smiling, clinging) are emitted. These behaviors function to re-establish proximity to the caregiver. The attachment system is thought to predominate over other behavioral systems (such as feeding and exploring) during times of separation or distress (Weiss, 1982; West \& Sheldon-Keller, 1994). Bowlby postulated this attachment behavioral control system in response to the inadequacies he believed existed within psychoanalytic and developmental learning theories which view attachment as arising from the satisfaction of more instinctual, primary needs (Cafferty, Davis, Medway, O’Hearn, \& Chappell, 1994).

Based upon his own observations of children faced with separation from caregivers as well as the observations of other researchers, Bowlby (1969) described three phases infants pass through in adjusting to a significant separation: protest, despair, and detachment. First, infants protest the separation, often crying intensely and showing angry responses until contact with the caregiver is re-established. If these attachment behaviors do not re-establish proximity to the caregiver, the infant will manifest despair reactions, such as whimpering, resignation, and withdrawal from environmental events. If the separation continues, the infant in time will become detached from its primary caregivers, showing renewed interest in its surroundings. If contact with caregivers is reestablished during this phase, infants react with apparent indifference to their gestures of 
contact. Bowlby observed that these three stages reliably and routinely occurred, despite the variation in duration and intensity of behaviors across infants. He also noted that these behaviors occurred in separated infants even if the institutions charged with the infants' care attended to their basic survival and medical needs.

Based upon these observations, Bowlby $(1969,1973,1980)$ described the normative processes involved in the development of an attachment relationship between an infant and its primary caregivers. All infants possess an attachment behavioral system that is activated during times of separation, and all infants separated from their caregivers go through phases of protest, despair, and detachment. Besides the proximity maintenance function of the attachment system, Bowlby also identified the attachment figure as being important in providing a secure base for the infant to explore its environment, as well as providing a safe haven to return to in times of perceived environmental threat. When the attachment figure is nearby, (s) he is used as a secure base from which the infant can safely venture into its surroundings to explore and manipulate the environment. However, if the infant perceives a threat in its environment, the attachment figure is quickly approached as a safe haven from surrounding dangers. Thus, the attachment behavioral system has, and the attachment figures serves, three interrelated functions for the infant: (1) a proximity maintenance to caregiver function, (2) a secure base from which to explore the environment function, and (3) a safe haven to return to when threats from the environment are perceived function.

Bowlby (1973) believed that as the infant interacts with its primary caregivers, it begins to develop expectancies about the availability and responsiveness of its caregivers 
toward its attachment needs. These expectancies are incorporated into what Bowlby called inner working models of attachment, which are essentially the product of attachment experiences the child has had within the attachment relationship. According to Bowlby (1973), "Confidence that an attachment figure is, apart from being accessible, likely to be responsive can be seen to turn on two variables: (a) whether or not the attachment figure is judged to be the sort of person who in general responds to calls for support and protection, and (b) whether or not the self is judged to be the sort of person towards whom anyone, and the attachment figure in particular, is likely to respond in a helpful way. Logically, these variables are independent. In practice they are apt to be confounded. As a result, the model of attachment figure and the model of the self are likely to be complementary and mutually confirming (p. 204)." Hence these inner working models are comprised of models of the self and models of other in the context of past experiences with a primary attachment figure. While primarily focusing on the normative aspects of attachment behavior, Bowlby's $(1982,1988)$ work on inner working models also suggested the importance of studying the individual differences in the attachment histories of infants.

Drawing from and building upon Bowlby's theory, Mary Ainsworth and her colleagues began to do systematic observations and laboratory experimentation into the individual differences exhibited in the quality of the attachment relationship between infant and caregiver (Ainsworth, 1967; Ainsworth, Blehar, Waters, \& Wall, 1978). While doing naturalistic observations of infant-mother interactions in Uganda and Baltimore, Maryland, Ainsworth et al. (1978) postulated that the quality of attachment within a 
particular infant-caregiver dyad may be in large part determined by the history of the interaction within the dyad and the degree to which the infant has come to expect a sense of 'felt security' when in close proximity to the parent. Based upon such observations, a laboratory procedure called the 'Strange Situation' was developed to assess the individual differences in infant-care giver attachment. This procedure, which consists of a number of episodes of contact, separation, and reunion with the primary caregiver and a 'stranger' to the infant, is designed such that the child's behaviors are observed and recorded under conditions of increasing stress and anxiety to the infant.

Based upon observations from the Strange Situation, Ainsworth identified and described three distinct patterns of attachment; secure attachment, insecure-resistant attachment, and insecure-avoidant attachment. Most of the infants (approximately 65\%) were classified as securely attached. During the Strange Situation, these infants exhibited a pattern of behavior characterized by signs of distress (crying and searching) during periods of separation from the caregiver, seeking comfort and using the caregiver as a safe haven upon reunion, and using the caregiver as a secure base by engaging in exploratory play in the attachment figures presence. During subsequent visits to the homes of securely attached infants, Ainsworth et al. (1978) found that the primary caregiver of these infants were generally sensitive to their signals and warm and responsive toward their needs.

Infants classified in the other two categories (resistant and avoidant) were seen as being insecurely attached in that the infant-caregiver interactions seemed to be of a poorer quality than those in the secure group. The insecure-resistant infants (approximately $10 \%$ 
of the sample) displayed protest behaviors and distress upon separation from the care giver, but intermingled proximity-seeking behaviors with overt anger and protest behaviors upon reunion with the attachment figure. During home visits, the caregivers of these infants displayed inconsistent responses to their infants' signals. At times these caregivers were emotionally unavailable and insensitive to such signals, and at other times they were overly intrusive in their interactions with their infants. The insecureavoidant infants (approximately $25 \%$ of the sample) exhibited few overt protest responses when separated from a caregiver, and tended to avoid approaching the caregiver and instead displayed detachment behaviors (e.g., averting gaze) upon reunion. The primary caregivers of these infants seemed to be rejecting, cold, rigid, and hostile to their infants' attempts at proximity during home observation visits.

Like Bowlby, Ainsworth (1989) believed that these early interactions between infant and caregiver lead to the development of inner working models of attachment. These models include representations of 'self' and of 'others' and are used by the infant to guide responses when distressed, as when separated from the caregiver. Therefore, the attachment patterns described by Ainsworth are the behavioral manifestation of these mental representations (Bretherton, Ridgeway, \& Cassidy, 1990; Grossmann \& Grossmann, 1991). Securely attached infants protest separation and seek comfort from an attachment figure upon reunion because past experiences have led the infant to expect these behaviors to relieve separation anxiety and to maximize the chances of reunion. Insecure-avoidant infants do not overtly express protest when separated from a caregiver because the infants have developed expectancies in which such signals are ignored or 
rejected by attachment figures. Insecure-resistant infants display a pattern of approach and avoidance behaviors when distressed, since their expectancies of caregiver responsiveness is one of inconsistency and insensitivity (Feeney \& Noller, 1996).

Attachment theory suggests that these inner working models guide behavior not only in infancy, but also in future romantic and social relationships as well. In other words, the relationship that characterizes a particular infant-caregiver dyad gives rise to mental representations of self and of others (and a specific pattern of attachment) which influence behaviors through childhood, adolescence, and adulthood (Main, Kaplan, \& Cassidy, 1985). Preliminary research into this possibility suggests that this may have some validity. For example, Elicker, Egeland, and Sroufe (1992) found that infant attachment patterns were reliably related to self-confidence and social skills at ten years of age. Children classified as securely attached as infants showed higher levels of selfconfidence and had better developed social skills compared to children classified as insecure-resistant or insecure-avoidant as infants. Other studies have found that security of attachment in infancy is able to predict a wide range of phenomena during the preschool and elementary school years, including school adjustment, quality of relationship with peers and non-parental adults, quality of familial relationships, and levels of distraction and need for discipline in school (see Lewis, Feiring, McGuffog, \& Jaskir, 1984; Erickson, Sroufe, \& Egeland, 1985; Waters, Wippman, \& Sroufe, 1979; Sroufe, Egeland, \& Kreutzer, 1990; Kobak \& Sceery, 1988; Londerville \& Main, 1981). Overall, considerable evidence exists that suggests that infant attachment patterns are related to emotional functioning and to behaviors displayed in toddler hood and early 
childhood. Using inner working models as guides for behavior, secure infants generally show better developed social skills and more appropriate interpersonal behaviors as young children than infants classified as resistant or avoidant. According to infant attachment theory, these working models should affect functioning within important relationships in adulthood as well, particularly behavioral and affective reactions during times of distress (Benoit and Parker, 1994).

\section{Adult Attachment}

While Bowlby and Ainsworth focused on bonds forged between infants and their caregivers in their observations and research, both contended that attachment behavior and relationships were important across the lifespan. According to Bowlby (1979), working models of these primary interactions become central components of personality such that behavior patterns influenced by them characterize humans "from cradle to grave (p. 129)." Ainsworth (1989) and Weiss (1991) identified the key components of attachment relationships between infants and caregivers. Based on their analyses, both researchers suggest that certain adult relationships share considerable overlap with aspects of the infant-caregiver dyad such that they could be considered 'attachments.' Such adult attachment relationships are characterized by long-lasting ties to a particular other, with whom one seeks closeness, comfort, and security (Ainsworth, 1989). Consistent with Bowlby's theory, the goals of such relationships appear to be proximity maintenance and a sense of felt security in times of distress (Feeney \& Noller, 1996). In particular, committed romantic relationships and certain long-standing friendships were identified as important attachments in adulthood (Ainsworth, 1985, 1989; Weiss, 1982, 
Hazan and Shaver's (1987) seminal article on romantic love and attachment grew directly from Bowlby's theory and Ainsworth's observations. Using attachment as a framework for studying adult romantic relationships, Hazan and Shaver (1987; Shaver, Hazan, \& Bradshaw, 1988; Shaver \& Hazan, 1988) noted the behavioral and emotional similarities within the attachment relationships of both infant-caregiver and adult romantic dyads. The desire for comfort, support, interdependency, trust, and physical contact was common across infancy-caregiver dyads as well as adult romantic partnerships. Shaver and Hazan (1988) suggested that experiences within early social relationships might have significant implications for and give rise to specific patterns of adult romantic attachments.

Based on their analysis of attachment theory and existing theories of love, Hazan and Shaver (1987) sought to empirically examine the parallels between attachment relationships in infancy and romantic relationships in adulthood. As the authors described their work, "So far, no one has attempted to conceptualize the entire range of romantic love experiences in a way that parallels the typology developed by Ainsworth and her colleagues. Nor has anyone with an interest in romantic relationships pursued Bowlby's idea that continuity in relationships style is a matter of mental models of self and social life. Finally, no one has explored the possibility that the specific characteristics of parent-child relationships identified by Ainsworth as the probable causes of differences in infant attachment styles are also among the determinants of adults' romantic attachment styles (pp. 512-513)." The purpose of their research was 
clearly focused on delineating individual differences in romantic relationships as suggested by Ainsworth et al.'s (1978) research, rather than on the normative aspects of attachment which Bowlby (1969) mainly described. Based on the secure, insecureavoidant, and insecure-resistant patterns of infant attachment identified by Ainsworth et al., Hazan and Shaver (1987) developed a self-report instrument of attachment style in adults. The items on the instrument were derived directly from the infant attachment literature, and particularly Ainsworth's descriptions of the secure pattern and the two insecure patterns of attachment. In addition, they were also interested in examining differences in the relationship experiences, inner working models, and attachment histories of adults exhibiting the three distinct patterns of attachment.

Based on results obtained from a large newspaper sample as well as an undergraduate sample, Hazan and Shaver's (1987) hypotheses relating attachment theory to romantic love were strongly confirmed. The proportions of adults endorsing particular patterns of attachment closely paralleled those obtained in the infant attachment literature. Specifically, approximately $56 \%$ of the adults described themselves as secure (compared to $62 \%$ in infants), $24 \%$ as avoidant ( $23 \%$ of infants), and $20 \%$ as anxious-ambivalent ( $15 \%$ of infants). This suggested that adults could meaningfully describe their relationship experiences and expectations using the self-report adult attachment pattern measure, and provided very preliminary evidence of continuity (at least in proportions) of the patterns of attachment from infancy to adulthood.

In addition, the relationship experiences, inner working models, and attachment histories of adults exhibiting different styles of attachment differed in theoretically 
meaningful ways, as predicted by the authors. Secure adults characterized their romantic relationships as trusting, satisfying, and friendly. In regard to inner working models, these adults described themselves as being well-liked and easy to get to know, and felt that others are generally good-hearted and trustworthy. Secure adults reported attachment histories characterized by warmth between the self and parents, as well as between their parents.

Adults who endorsed the avoidant pattern of attachment had romantic relationships that were characterized by fears of intimacy and wariness of becoming too close to partners. In describing their attachment histories, these adults tended to describe their mothers as being cold and rejecting. Avoidant adults also seriously questioned the validity of enduring romantic relationships.

Finally, adults who endorsed the anxious-ambivalent pattern of attachment described romantic relationships marred by preoccupation with partners, jealousy, and emotional highs and lows. The mental models of these adults suggested that they have a number of self-doubts about themselves, and that they view themselves as being misunderstood and under appreciated by others. They also felt that they were more committed to their relationships than were their partners. Also, anxious-ambivalent adults described their mothers as misunderstanding them, and their fathers as cold and uncaring.

While acknowledging the methodological limitations of their research, Hazan and Shaver's (1987) relatively brief, self-report instrument of adult attachment patterns translated from descriptions of Ainsworth et al.'s styles of infant-caregiver attachment 
seems to robustly and meaningfully relate to processes involved in adult romantic relationships. Their theoretical analysis of love as an attachment process and empirical work on adult styles of attachment were highly influential in later studies of interpersonal processes in adulthood.

In particular, their results encouraged researchers to replicate their findings of the relationship between attachment and romantic love, and to extend these findings to related theoretical concepts (Hazan \& Shaver, 1994a, 1994b; Shaver \& Hazan, 1993). Subsequent research based on their studies has suggested that adult attachment styles influence relationship satisfaction and other interpersonal processes (Hammond \& Fletcher, 1991; Pistole, 1989, 1995; Kirkpatrick \& Davis, 1994; Simpson, 1990; RadeckiBush, Farrell, \& Bush, 1993; Senchak \& Leonard, 1992), working models of self and others (Baldwin, Fehr, Keedian, Seidel, \& Thomson, 1993; Baldwin, 1995; Collins \& Read, 1990), and past attachment experiences (Feeney \& Noller, 1990). Other researchers have studied adult attachment patterns and their relationship to personality traits (Shaver \& Brennan, 1992; Williams \& Schill, 1994), to certain love styles (Levy \& Davis, 1988; Sperling \& Berman, 1991), and to therapeutic counseling processes (Lopez, 1995; Bartholomew \&Thompson, 1995). Generally, results of these studies indicate that securely attached adults have more satisfying romantic relationships, have more positive and optimistic images of the self and of others, and have more positive perceptions of their early family relationships than avoidant and anxious-ambivalent adults. The attachment patterns proposed by Hazan and Shaver (1987) seem to be an effective and useful typology for explaining some of the individual differences evident in certain 
interpersonal and intra-personal processes. Much of the research following their studies replicated their original findings, while at the same time addressing some of the conceptual and methodological limitations they noted (see Feeney \& Noller, 1996).

Hazan and Shaver (1987) drew their theory of adult attachment styles directly from the observations of Ainsworth et al. (1978). In doing so, they simply translated the components of the secure, insecure-avoidant, and insecure-resistant styles of infant attachment into terms appropriate for adults. In proposing and developing a twodimensional model of adult attachment, Kim Bartholomew (1990) looked to Bowlby's (1973) theory of inner working models of attachment as a starting point, rather than to the later empirical work of Ainsworth. Being based on the theoretical logic of attachment theory as originally proposed by Bowlby, Bartholomew's model is not as removed from the theory's origins as that of Hazan and Shaver.

The two dimensions of Bartholomew's (1990) model are based on Bowlby's (1973) contention that infants develop inner working models of both self and of others. Bowlby felt that these working models provided the prototypes for later social relationships as the child matures toward and through adulthood. Bartholomew (1990; Bartholomew \& Horowitz, 1991) began to construct a theory of adult attachment based on these two dimensions of working models; views of the self and views of others.

According to Bartholomew (1990), model of the self and model of others could each be dichotomized to form four prototypic attachment patterns of attachment. The self could be viewed as being worthy of love and attention (positive self-model), or the self could be viewed as being unworthy of affection (negative self-model). Along these same 
lines, others could be seen as available, trusting, and caring (positive other-model), or others could be viewed as unavailable, rejecting, and distant (negative other-model). Accordingly, "The positivity of the self model indicates the degree to which individuals have internalized a sense of their own self-worth and therefore expect others to respond to them positively; thus, the self-model is associated with the degree of anxiety and dependency experienced in close relationships. The positivity of the other model indicates the degree to which others are generally expected to be available and supportive; thus, the other model is associated with the tendency to seek out or avoid closeness in relationships (p. 431, Griffin \& Bartholomew, 1994)."

Four prototypic patterns emerge when the model of self is considered in conjunction with the model of others. The secure pattern is characterized by an internalized sense of being worthy of love, acceptance, and support and an expectation that others are responsive, accepting, and trustworthy (positive self/positive other). The secure pattern of attachment is similar conceptually to the secure pattern identified by Hazan and Shaver (1987) as well as Main, Kaplan, and Cassidy (1985). The latter researchers assess attachment via the Adult Attachment Interview (AAI), which asks adults about memories related to childhood experiences with caretakers (George, Kaplan, \& Main, 1985; Main \& Goldwyn, 1985). Despite different theoretical underpinnings, the three methods all identify a secure group that exhibits positive self-regard and comfort in approaching others (Bartholomew \& Horowitz, 1991).

The preoccupied pattern, which corresponds to Hazan and Shaver's (1987) anxious-ambivalent group and Main et al.'s (1985) enmeshed group, believe themselves 
to be unworthy of love and support while relationships with other people are highly valued (negative self/positive other). This group builds a sense of self-regard and selfesteem through gaining the acceptance of others. This pattern of needing to validate one's self-worth through preoccupation with intimacy needs is also evident across all attachment schemes (Bartholomew \& Horowitz, 1991).

The fearful pattern is characterized by feelings of being unworthy of love and acceptance and a view of others as being rejecting, hostile, and untrustworthy (negative self/negative other). Bartholomew and Horowitz (1991) suggest that this fearful pattern of attachment is similar to the avoidant group discussed in Hazan and Shaver's (1987) typology. Both groups appear to approach relationships with some trepidation, distress, and discomfort. By distancing themselves from others, they circumvent the feared rejection and hostility they expect to result from social relationships.

Finally, the dismissing pattern is characterized by feelings of high self-regard and self-acceptance, but a stance of detached distrust and distance toward others (positive self/negative other). Bartholomew and Horowitz (1991) describe the dismissing pattern as being similar to the dismissive-avoidant group identified by Main et al. (1985) in that both seem to deny (possibly defensively) the need for intimacy and closeness in relationships. Hazan and Shaver (1987) did not discuss explicitly such a pattern in their attachment categorization.

While both the dismissing and fearful patterns of attachment described by Bartholomew (1990) share a negative working of model of others, each approach relationships differently. As described by Griffin and Bartholomew (1994), “Fearful 
individuals are highly dependent on others for validation of their self-worth; however, because of their negative expectations of others, they shun intimacy to avoid the pain of potential loss or rejection. Dismissing individuals also avoid closeness with others because of negative expectations; however, they maintain their high sense of self-worth by defensively denying the value of close relationships and stressing the importance of independence (p. 431)." Dismissing individuals are thought to maintain a positive sense of self-regard through involvement in impersonal activities such as work, hobbies, or sporting activities (Bartholomew, 1990).

Based on this two-dimensional, four category system, Bartholomew and Horowitz (1991) developed a self-report instrument to measure adult attachment patterns similar to the Hazan and Shaver (1987) measure. The Relationship Questionnaire (RQ) contains descriptions of the four prototypical attachment patterns. Subjects are asked to decide which pattern best describes their orientation toward current, valued relationships. Subsequent work has confirmed the construct validity of the self and other dimensions which are the basis of the measure, and suggest that the four attachment patterns demonstrate predictive validity for certain intra-personal and interpersonal phenomena (Griffin \& Bartholomew, 1994; Bartholomew, 1994) (see methodology section for further details).

As the field appears to be shifting toward Bartholomew's (1990) expanded four category attachment scheme, there is a need to replicate and extend previous studies that utilized Hazan and Shaver's (1987) now dated three category measure. Brennan, Shaver, and Tobey (1991) cross tabulated results gained from the RQ and the Hazan and Shaver 
measure. As expected, they found that subjects who described themselves as secure on the RQ also chose the secure pattern on the three category measure, while adults who chose the preoccupied pattern on the RQ described themselves as anxious-ambivalent on the Hazan and Shaver measure. As described earlier, the primary difference between Bartholomew's (1990) and Hazan and Shaver's (1987) systems is that the former describes two types of 'avoidant' attachment (dismissing and fearful) while the latter has one avoidant category (termed avoidant). In addition, Bartholomew derived her system directly from Bowlby's theory while Hazan and Shaver drew their ideas primarily from Ainsworth's later work on patterns of infant-mother attachment. Cross tabulations of the two systems indicate that Bartholomew's fearful group generally endorse Hazan and Shaver's avoidant pattern, while Bartholomew's dismissing group comes from both Hazan and Shaver's secure and avoidant groups (Brennan et al., 1991). Support for the four category model of adult attachment is further bolstered by studies of infant attachment where a fourth pattern of infant-caregiver attachment was recently identified. Brennan et al. (1991) suggest that this disorganized attachment pattern in infancy may be similar to fearful attachment in adults since both are indicative of the most severe insecurity across attachment schemes.

In addition to studying points of intersection between the four category system and previous attachment measures, researchers have utilized the RQ to explore a variety of intra-personal and interpersonal processes. Within the intra-personal realm, for example, secure and dismissing adults tend to have higher levels of self-esteem and selfperceived competence (Byslma, Cozzarelli, \& Sumer, 1997; Davila, Hammen, Burge, 
Daley, \& Paley, 1996; Griffin \& Bartholomew, 1994) and appear to regulate affective information more effectively (Davila et al., 1996; Diehl, 1998) than preoccupied or fearful adults. Additionally, Zuroff and Fitzpatrick (1995) found that fearful adults tend to engage in more self-criticism and that preoccupied adults are more dependent on others for maintaining their self-esteem than secure or dismissing adults.

Within the interpersonal realm, Bartholomew's (1990) four attachment patterns have been shown to be correlated with relationship orientation and satisfaction in theoretically expected ways (Griffin \& Bartholomew, 1994; Diehl, 1998) as well as reactions to relationship dissolution (Pistole, 1995). Secure adults appear to have a more positive orientation toward relationships and more successful, satisfying relationships than insecure adults, while both secure and dismissing adults reported more positive emotional experiences after a romantic break-up than preoccupied or fearful adults. The four patterns have also been shown to be associated with certain interpersonal problems and adjustment. For example, secure adults were described as being warm interpersonally by both self and friend report. Dismissing adults were associated with ratings of hostility and coldness, preoccupied adults with dominance and overexpressiveness, and fearful adults with unassertiveness and social inhibition (Horowitz, Rosenberg, \& Bartholomew, 1993; Horowitz, 1996; Kenny \& Rice, 1997). This preliminary work based on Bartholomew's typology has indeed replicated many of Hazan and Shaver's findings, while at the same time allowing for more detailed discriminations of the avoidant attachment pattern. The purpose of this study is to extend these findings further by examining adults reactions to a real-life, stressful separation through the lens of 
the mental models associated with the secure, dismissing, preoccupied, and fearful patterns of attachment.

\section{Attachment, Separation, and Responses to Distress}

Attachment theory as discussed by Bowlby $(1969,1973,1980)$ was conceptualized in response to his observations of infants' reactions to separation from caregivers. He noted that infants reliably go through a sequence of responses characterized first by protest (crying, anger, searching), then despair (emotional withdrawal, depression, and anxious reactions), and finally by detachment (emotional detachment from caregiver). In their description of infant patterns of attachment, Ainsworth et al. (1978) based their findings on infant reactions to separation from and reunion with a caregiver in a laboratory situation. Despite the fact that emotional reactions to separation and loss are a central tenet of attachment theory, little attention has been given to adults' reactions to separation from attachment figures, and no study has examined Bartholomew's (1990) four-category system in relation to separation experiences. The studies that have been done have focused on one of four types of separation: (1) the transition from home to college, (2) wartime separation, (3) marital separation or divorce, and (4) death.

Studies of students' reactions to leaving the home environment and their transition to college have generally focused on the effects of parental attachments. For example, Kenny (1987) examined students' descriptions of and the functions of parental relationships after an adolescent moved out of the home. She found that the students' descriptions resembled the secure prototype described by Ainsworth et al. (1978). In 
addition, she found that while away at school, parents served as a secure base for their children by encouraging their independence and exploration as well as a safe haven or support system the adolescent could turn to in times of stress. Berman and Sperling (1991) examined normative changes in parental attachment over time as students adjusted to a college environment. Generally, they found that parental attachment decreased over time as students discovered and developed other attachment relationships. In addition, they found that high parental attachment at the onset of college was predictive of depression for males as compared to students with lower levels of parental attachment. Rice, FitzGerald, Whaley, and Gibbs (1995) studied parental attachments among college students and their relationship to college adjustment. In cross-sectional and longitudinal studies, they found that security of parental attachment was stable over a two year period. In addition, compared to students with insecure attachments to parents, secure parental attachments were positively correlated with academic, social, emotional, and curricular adjustment and were negatively correlated with separation anxiety.

Mayseless, Danieli, and Sharabany (1996) examined adult attachment patterns and coping with separations using Hazan \& Shaver's (1987) three-category attachment system. Their sample consisted of a college sample with a mean age of close to 25 years, which is significantly older than other college transition studies. Secure adults were described as being in the process of gradually becoming adjusted to being separated from their parents. They tended to live outside their parents' homes and to be involved in close, committed romantic relationships. On a projective test (The Separation Anxiety Test or SAT), secure adults were able to differentiate between mild (temporary, everyday 
separations) and severe separations. These adults tended to have marked attachment reactions (protest, despair) only to severe separations.

Anxious-ambivalent adults also lived outside the home, but were less successful in finding close, committed romantic relationships. These adults tended to react strongly on the projective measure (the SAT) to both mild, everyday separations as well as more severe, permanent separations. They reacted to these imagined separations with strong attachment reactions, anxiety, feelings of rejection, and self-blame. The authors felt that anxious-ambivalent adults were struggling with separating from their parents, and that this struggle seemed to impair their functioning as well as exploration of other adult romantic relationships.

Avoidant adults tended to still live with parents and not to have developed close, romantic relationships. On the SAT, these adults had fewer attachment reactions to imagined separations. The authors described these adults as reacting with diminished involvement by avoiding conscious perception of alarming responses to imagined separations. The authors suggest that avoidant adults are reluctant to tackle the task of separation from their parents.

Several studies relate attachment and responses to war-time separations. Vormbrock (1993) examined war-time separations and short-term and long-term jobrelated separations. She found that despite differences in the type and duration of these separations, emotional reactions were similar to the sequence of protest, despair, and detachment observed by Bowlby in infant samples. Cafferty et al. (1994) examined separation reactions and reunion dynamics of couples separated because of military 
deployment in Operation Desert Storm. Using the three pattern scheme of Hazan and Shaver, they found that securely attached adults exhibited higher levels of marital satisfaction and lower levels of conflict during reunion than insecurely attached adults. Preoccupied adults had the lowest levels of marital satisfaction and the highest levels of post-reunion conflict. During periods of separation, securely attached adults reported higher levels of wellness than avoidant adults. Preoccupied adults did not differ significantly from either of these groups in reported wellness, but their scores were very similar to avoidant adults' ratings. In a related study, it was found that insecurely attached adults felt greater stress when their partner was deployed than securely attached adults (Medway, Davis, Cafferty, Chappell, \& O’Hearn, 1995).

Other researchers have examined post-divorce and death experiences from an attachment perspective. Working from Bowlby's perspective, Weiss (1975) described the role of attachment in the development of romantic relationships which lead to marriage, and suggested how these attachments can continue after the relationship is legally dissolved through divorce. Similar to the mourning reactions described by Parkes (1973) and Clayton (1990), post-divorce experiences may include recurrent images of the partner, feelings of loneliness and depression, feelings of anxiety because the spouse is not accessible, and fruitless attempts to contact the partner. Weiss $(1975,1982)$ argues that such reactions are the result of the inaccessibility of the attachment figure upon which one has come to depend. After divorce or death, the remaining partner no longer has that primary attachment figure who can be used as a secure base from which one can face obstacles in life or a safe haven to return to for comfort and support in times of stress 
(Weiss, 1982; Glick, Weiss, and Parkes, 1974). Gray, Kroopman, and Hunt (1991) found in a sample of recently divorced men and women the three predictable phases of protest, despair, and detachment described in Bowlby's theory of loss of an attachment figure. Similarly, Berman (1988a, 1988b; Berman, Marcus, \& Berman, 1994) found that a positive attachment to an ex-spouse was associated with exacerbated subjective distress and poor coping response to divorce, while a negative or neutral attachment to an exspouse was associated with less distress and enhanced coping.

Overall, then, the literature relating attachment to reactions to separation is scarce, particularly empirical investigations of individual differences in separation reactions associated with patterns of attachment. No published articles have explicitly examined Bartholomew's typology in relation to emotional reactions to separations, and only one has used the Hazan and Shaver typology. In addition, Bowlby's observations of infants focused on unexpected, uncertain, and stressful long-term separations. The studies just reviewed have typically involved expected developmental transitions (e.g., going away to college), have focused on situations where the attachment figure is permanently inaccessible (e.g., death of a spouse), or have examined expected or even desired separations (e.g., job related separation, military deployment, divorce or marital separation). These separations differ in important ways (volition, duration, permanency, predictability, etc.) from those Bowlby studied. What have been more thoroughly investigated from the perspective of attachment are affect regulation strategies and emotional responses to distress. This literature may shed some light on the expected relationship between differences in separation reactions and adult attachment patterns. 
According to Bowlby (1969), acute and chronic stressors should activate attachment behaviors such as to regain proximity to trusted others. Hence, particular affect regulation strategies and responses to such stressors should differ by the pattern of attachment a particular person exhibits. Simpson, Rholes, and Nelligan (1992) examined support seeking and support giving within romantic dyads during an anxiety provoking laboratory situation from an attachment perspective. They found that secure women tended to seek support as levels of anxiety increased, while secure men tended to offer more support to their partner as she became more anxious. Avoidant women, however, sought less support as their anxiety increased, while avoidant men offered less support to their partner with increasing anxiety. They found no differences among anxiousambivalent men or women.

Priel and Shamai (1995) examined attachment styles and their relationship to perceived social support and affect regulation strategies. They discovered that securely attached adults are less depressed and anxious then avoidant and anxious-ambivalent adults. They also found that avoidant subjects tended to regulate internal distress slightly better than anxious-ambivalent adults, who were the most depressed and anxious group. In addition, secure adults had significantly larger social support networks and were more satisfied with their perceived support than either group of insecure subjects.

In a particularly provocative study looking at affect regulation strategies by attachment pattern, Brennan and Shaver (1995) looked at differences in specific unhealthy behaviors including non-intimate sexual behavior, eating disorders, and alcohol consumption patterns. Compared to securely attached adults, avoidant subjects drink 
larger quantities of alcohol and use alcohol to reduce stress and anxiety, and avoid intimacy within romantic relationships by fantasizing about sexual encounters with other people and by engaging in brief sexual encounters which they consider to be meaningless. Anxious-ambivalent (or preoccupied) subjects also drank to reduce stress and anxiety, and further, tended to have symptoms of eating disorders such binging under conditions of stress.

Mario Mikulincer and his colleagues did a series of studies using Hazan and Shaver's (1987) attachment typology to examine coping strategies, self-disclosure, and perceived social support. For example, it was found that secure adults use more supportseeking strategies when distressed, while anxious-ambivalent adults used more emotionfocused strategies and avoidant adults used more distancing strategies under similar conditions. In addition, anxious-ambivalent adults exhibited higher levels of anxiety, depression, hostility, and somatization while avoidant adults showed higher levels of hostility and somatization relative to secure adults under stressful conditions (Mikulincer, Florian, \& Weller, 1993; Mikulincer, Florian, \& Tolmatz, 1990).

In a similar study, secure individuals were found to appraise distressing situations in less threatening terms than both groups of insecure subjects, and to see such situations as more of a challenge to be met than anxious-ambivalent adults. The authors suspect that the internal working models of secure adults allow such a non-threatening appraisal, which gives them a sense of inner strength to handle stressful situations. Anxiousambivalent adults tend to be hyper-vigilant of their own affect and tension when distressed, while avoidant adults tend to distance themselves emotionally from threats 
(Mikulincer \& Florian, 1995). In studies of perceived social support and patterns of selfdisclosure to others, it was found that secure adults perceive higher levels of support and report seeking emotional support more readily than avoidant and anxious-ambivalent adults (Mikulincer \& Nachson, 1991; Mikulincer \& Avev, 1991). They also found that secure and anxious-ambivalent adults self-disclosed to others more readily, and additionally, disclosed more personal information to, felt better interacting with, and were more attracted to a self-disclosing person than were avoidant adults. Secure individuals, however, were more responsive to a partner's disclosures than were anxious-ambivalent subjects.

As in the separation literature, none of the studies above utilized the twodimensional, four category classification scheme. While results relating to Hazan and Shaver's secure and anxious-ambivalent subjects should be applicable to Bartholomew's secure and preoccupied groups respectively, it is unclear what pattern would emerge if subjects had the opportunity to describe themselves as either dismissing avoidant or fearful avoidant. In light of the fact that people who endorse Bartholomew's fearful pattern are largely comprised of people who endorsed Hazan and Shaver's avoidant pattern, and that those who endorse Bartholomew's dismissing group are drawn from both Hazan and Shaver's secure and avoidant groups, the above findings become even less clear.

Despite this difficulty, it is clear that people exhibiting different patterns of attachment utilize distinct affect regulation strategies under stressful conditions. Stressful, threatening environments should activate one's inner working model of 
attachment, which differs by attachment pattern. One such threatening environment is incarceration within a penitentiary. Incarceration involves an unexpected, undesired separation from one's primary attachment figure(s), and placement in what is often perceived to be a hostile, threatening environment. Normally such a threat to well-being should activate attachment behaviors that enhance the accessibility to attachment figures. However, incarceration effectively cuts one off from such supportive figures, leaving one only with whatever internal resources an individual possesses. Under such conditions, what sort of affective and behavioral reactions are likely to result? Further, will patterns of attachment, which are thought to develop from one's historic interactions with significant others, have an effect on these affective and behavioral responses as one adjusts to a prison environment? Finally, what other variables have been shown to be associated with prison adjustment? Studies of inmates' reactions to prison environments may highlight such variables associated with either a more adaptive or maladaptive prison adjustment.

\section{Prison Adiustment and Adaptation}

Researchers working within correctional settings have historically examined variables that co-vary with adjustment to prison environments. Adjustment is operationalized by the majority of these researchers as prison behavior, or more aptly, prison misbehavior. The aim of much of the early research in this area was to find variables that were predictive of prison misbehavior to aid in the classification of inmates to appropriate security levels (Thomas, 1977). The disciplinary records of inmates were typically examined to see if a relationship existed between more extensive prison 
disciplinary histories and certain background characteristics of inmates. The most established and robust correlate of disciplinary involvement appears to be the inmates' age at admission to the correctional setting (Myers \& Levy, 1978; Petersilia \& Honig, 1980; McShane \& Williams, 1989). Across most studies of this type, younger inmates tend to have more serious and extensive disciplinary records than older inmates. Other variables such as ethnicity (Myers \& Levy, 1978), type of criminal offense (Brown \& Spevacek, 1971), and certain personality profiles (Megargee \& Bohn, 1977) have also been associated with disciplinary difficulties within prisons.

In a review of the most recent literature on prison adjustment, many of these same variables still appear to be associated with more extensive disciplinary records. Adams (1977) found that inmates who had dropped out of school, who had prior training school records, who had dishonorable discharges from the military, and/or who exhibited employment instability tended to have more extensive disciplinary records than a control group of inmates. Adams suggested that a significant history of societal maladjustment might affect inmates' adjustment to prisons. Flanagan (1983) found that prison misconduct was related statistically significantly to the age, pre-prison employment status, marital status, ethnicity, and substance abuse history of inmates. Generally, young, unemployed, single, non-white, and drug addicted inmates tend to have more serious disciplinary infractions than other inmates. Similarly, Toch and his colleagues found that young, unmarried, unemployed, uneducated inmates with no previous prison experience were more likely to have higher rates of disruptive prison behavior. In addition, they also found an relationship between inmate psychopathology and disruptive 
behavior (Toch \& Adams, 1986; Toch, Adams, \& Greene, 1987). Wright (1989) found that regardless of race, economic marginality predisposed an inmate toward disciplinary involvement.

Other researchers have examined environmental differences in prisons and their affects on inmate adjustment. For example, Walters (1991) found that more structured prison environments are positively related with better inmate adjustment. In addition, Smyth and Ivanhoff (1994) found that inmates who prefer activity and social stimulation adapt better to the prison environment than inmates who prefer privacy or expect to have more freedom while incarcerated.

Still other researchers have operationalized prison adjustment differently than disciplinary records. MacKenzie, Shaw, and Souryal (1992) found that inmates who are younger at first arrest and at time of incarceration, who are non-white, and who have shorter sentences adjusted less well according to staff reports to community supervision. Ivanhoff (1992) found that inmates with a psychiatric history and with social support networks that contain people with an arrest record are at risk for parasuicide attempts while incarcerated. Pugh (1993) found that an internal locus of control was related with better scores on self-report measure of prison adjustment. Finally, Silverman and Vega (1990) found that inmates who are younger, unmarried, and who have not graduated from high school are more likely to exhibit symptoms of anxiety, depression, and hostility and perceive more environmental stressors than other inmates.

In addition to examining background and demographic correlates of prison adjustment, other researchers have focused on changes in adjustment to incarceration 
over time. In a sample of inmates who had engaged in para-suicidal behavior, there were statistically significant decreases in depression, suicidal ideation, and suicide attempt expectancy, as well as increases in perceived quality of life over a one year time span (Smyth, Ivanhoff, \& Jang, 1994). In a study of the impact of long term incarceration, inmates exhibited no psychological deterioration over time. In fact, the earliest period of incarceration was the most stressful for inmates, as evidenced by the most elevated levels of anxiety, depression, psychosomatic illness, and fear of other inmates, as well as the lowest levels of self-esteem, occurring during the first year of imprisonment (MacKenzie \& Goodstein, 1985). In a study of inmates at a Scottish detention center, self-esteem increased over time while levels of hopelessness and distress tended to decrease over time of the prison sentence (Power \& Beveridge, 1990).

Toch, Adams, and Grant (1989) examined the disciplinary histories of inmates who had exhibited poor adjustment to the prison environment. They discovered what they termed a period of "transition shock" at the onset of these inmates' sentences. A majority of these inmates' difficulties occurred in the first six months of their sentences, and problem behaviors tended to decrease with time. In a review of the relevant literature, Bonta and Gendreau (1990) also identified the initial adjustment phases as being the most important in assessing the impact of incarceration. They noted that if an inmate either reports or exhibits distress or problem behaviors, they often occur early in the inmate's sentence.

Schmid and Jones (1993) examined the prison adjustment strategies of short-term incarcerated inmates. In the early part of their sentences, inmates often exhibited anxiety, 
particularly relating to fears of violence occurring to them within the prison and the uncertainty of contact with outside family and friends. Over time, however, this anxiety, uncertainty, and fear was replaced by boredom as one became familiar with the prison setting. In addition, inmates exhibited signs of detachment from loved ones as time passed and wanted to discontinue outside contacts at times as a means of coping with their incarceration.

In a particularly provocative study, Zamble and Porpino $(1988,1990)$ examined the coping behaviors of inmates over the first year and a half of their sentences. At the beginning of their sentences, a large proportion of the inmates interviewed were experiencing elevated levels of depression, anxiety, guilt, and sleep disturbance and low levels of self-esteem as they adjusted to their surroundings. However, emotional distress decreased significantly when inmates were tested three months later, and had dropped further still after one year, while self-esteem increased over the same period. Emotional distress decreased even more when inmates were re-tested seven years after the beginning of their sentences (Zamble, 1992). In describing this pattern of results, Zamble and Porpino $(1988,1990)$ felt that the elevated symptoms of emotional distress were the result of the "shock" of imprisonment. With time, this shock wears off leaving the inmate in what they called a "behavioral deep freeze" for the remainder of their term. This 'freeze' results from inmates becoming accustomed to their surroundings, and is evidenced by reduced emotional distress and disciplinary violations. This pattern of initial transition distress of inmates, followed by a return to baseline levels of behavior is similar to the sequence described by Toch et al. (1989) as well as Schmid and Jones (1993). 
In addition to studying the emotional distress experienced by inmates, Zamble and Porpino $(1988,1990)$ also asked their subjects what were the major problems they faced personally while in prison. They had subjects rank order the most difficult problems they dealt with in adjusting to prison. According to the Zamble and Porpino (1988), "The great majority of subjects were troubled by the separation from loved ones on the outside, and for most of them the problem of missing someone ranked near the top of their lists. This category clearly dominates the choices. Problems with loss of freedom because of imprisonment comprised the second most frequent category, but this was listed by only about half the subjects who had reported missing people....The ever-present absence of loved ones presents itself often and unpredictably, in small ways as well as large (p. 116)." In fact, 107 of the 133 inmates (82\%) included in their study stated that missing family or friends was a significant difficulty they faced. This replicates findings of Richards (1978), who found that "missing somebody" was the most severe problem described by a group of inmates serving lifetime sentences. As discussed by Schmid and Jones (1993) and Bonta and Gendreau (1990), family separation presents a unique and very salient difficulty for inmates as they adjust to incarceration.

Similarly, Flanagan (1981) interviewed a group of inmates sentenced to long-term incarcerations and found that separation from loved ones and maintenance of family and friendship ties was a principal deprivation the men were forced to deal with. Harris (1993), in describing the pains of imprisonment for inmates, discussed the lack of emotional support due to separation from family and friends as particularly stressful to subjects. A variety of research findings has determined that imprisonment can lead to an 
inmate experiencing emotional anguish because of physical separation from family and other important social relationships (King, 1993; Hairston, 1987; Schneller, 1978), and how such separations can have detrimental effects leading to family disintegration (Carlson \& Cervara, 1991; Jorgenson, Hernandez, \& Warren, 1986; Koenig, 1985). Current family conflict and the number of visitors an inmate receives have even been found to relate to prison adjustment. The more conflict, which characterized an inmate's family, and the fewer visitors an inmate receives, the more likely that the inmate is involved in prison misconduct (Kemp, Glaser, Page, \& Horne, 1992; Borgman, 1985; Thomas, 1971). However, research into individual differences in prison adjustment related to relationship variables (such as attachment patterns) is scarce, with the majority of studies focusing on normative processes involved in inmate separation from loved ones. Despite this shortcoming, the research findings seem to clearly indicate that it is separation from family and friends that a vast majority of inmates find to be the most stressful and distressing aspect of being incarcerated. In light of this, adult attachment patterns may be particularly influential in explaining the individual differences evident in studies of prison adjustment since they are based upon observations of what seems to happen when one is separated from cherished others.

\section{Attachment and Prison Adjustment}

There are very few published articles examining attachment and inmate characteristics, and none that explicitly examine attachment and prison adjustment. Using Bartholomew's model of adult attachment, Pistole and Tarrant (1993) looked at the relationship between attachment style and hostility in a sample of men convicted of 
assault against a romantic partner or family member. Among their results they found that the proportions of attachment styles in their sample were similar to those reported in nonviolent groups. Marshall $(1989,1993)$ and his colleagues developed a theoretical framework examining the role of attachment in the etiology of sexual offending (Marshall \& Mazzucco, 1995; Ward, Hudson, Marshall, \& Siegert, 1995). Marshall describes insecure attachment as a general vulnerability factor for criminality in general, and posited a specific relationship between patterns of attachment and particular forms of sexual offending (e.g., child molestation, rape, etc.). In the one empirical study based on this framework, it was found that a majority of their incarcerated sample rated themselves as being insecurely attached on the RQ in their relationships with romantic partners, as they had predicted. They also found some preliminary evidence that types of sexual offending may be related to particular patterns of attachment (Ward, Hudson, \& Marshall, 1996).

Despite the lack of published articles, it appears that attachment theory would be a useful framework for examining prison adjustment. Attachment theory is based upon observations of what happens when an infant is separated from its primary caregiver(s), and in particular their emotional and behavioral reactions to such separations (Bowlby, $1969,1973,1980)$. Infant attachment patterns are based upon a laboratory procedure where an infant is temporarily separated from a caregiver. Certain patterns of emotional and behavioral responses occurred during these periods of separation (as well as reunion) which Ainsworth et al. (1978) identified and described in detail. Similarly, incarceration involves being separated from cherished family members, friends, and other social 
relationships. Some inmates react with depressive symptoms, some with anxiety, and some do not appear to have any particular adverse emotional reactions to being incarcerated. Also, certain inmates react to imprisonment by behavioral acting out which results in a high rate of disciplinary violations, while other inmates go through their sentence with no disciplinary reports whatsoever. Thus, there appears to be wide variability in inmate adjustment to the prison environment.

In adapting to the prison, one of the most challenging problems an inmate faces appears to be dealing with separation from loved ones. When asked about the major problems a newly incarcerated inmate must deal with, the most commonly cited difficulty is being physically and emotionally separated from loved ones (Zamble \& Porpino, 1988; Bonta \& Gendreau, 1990). This may be particularly salient for inmates since such separations are usually unexpected, undesired, and outside of one's control. Inaccessibility to loved ones is usually not permanent, but it is severely disrupted, constricted, and governed by outside forces (the prison's visiting policies). These are the very sorts of separations from attachment figures discussed and observed by Bowlby (1969) and Ainsworth et al. (1978) in infants. The few studies conducted on adult attachment have examined separations that are desired (e.g., divorce or marital separation), expected (e.g., college transition, military training), or permanent (e.g., death of a spouse), and have not utilized Bartholomew's four category scheme, which is firmly grounded in Bowlby's original framework.

In addition, a number of researchers have identified the initial few weeks or months of incarceration as being the most difficult for inmates. The first weeks of 
imprisonment, identified as a period of 'transition shock' in the literature, is characterized by elevated numbers of emotional adjustment reactions and the highest rates of disciplinary infractions by inmates. With time, however, measures of depression, anxiety, anger, and self-esteem tend to return to normal levels, and the number of disciplinary infractions tends to decrease significantly (Zamble \& Porpino, 1988, 1990; Toch et al., 1989). This pattern of initial angry outbursts and elevated levels of depression and anxiety and lowered self-esteem followed by a return to 'normal' levels of these constructs appears to be very similar to the sequence of events Bowlby identified in infants separated from their caregivers. When dealing with such separations, Bowlby (1969) noted that infants initially express protest (crying, angry outbursts), then despair (resignation, withdrawal from environmental events), and finally detachment from original attachment figures (renewed interest in their surroundings). This sequence of events (initially high levels of anxiety, depression, and angry outbursts followed by decreasing emotional and behavioral difficulties over time) appears to be quite similar to reactions inmates exhibit in adjusting to the prison environment.

In light of the fact that a majority of inmates appear to identify separation from loved ones as the most difficult obstacle they face at the onset of their sentences, could the adjustment reactions they exhibit be explained in part by patterns of attachment? Bartholomew's (1990) two-dimensional model of attachment posits four distinct patterns of attachment. The general trend in such studies is that the secure pattern is associated with more satisfying, trusting, interdependent romantic relationships compared to the three insecure patterns of attachment. The security one has in one's attachment 
relationships may moderate how inmates react to separations from loved ones while incarcerated. If one is insecure in the availability of others in general, what affect will this have on one's reaction to being incarcerated where one is physically separated from attachment figures? Indeed, studies of this kind have not been published to date.

In addition, the valences of the self and of the other models which underlie each pattern of attachment may moderate prison adjustment reactions. The secure and dismissing attachment patterns both have a positive self model and have been associated with higher levels of self-esteem, self-regard, self-perceived competence, and general intra-personal functioning (Bylsma et al. 1997), and appear to regulate affective information more effectively (Davila et al., 1996; Diehl, 1998) than preoccupied or fearful adults. These latter patterns have a negative model or image of the self. It is possible that the strong internal resources associated with the secure and dismissing attachment patterns may be related to more positive, less aversive reactions to imprisonment. In addition, the dismissing and fearful attachment patterns have inner working models with a negative expectation of others while the secure and preoccupied patterns highly value intimacy with others. The value one places on involvements with others based upon ones inner working model of 'others' may also mediate prison adjustment reactions.

The dismissing attachment pattern (positive self/negative other) is characterized by feelings of high self-regard and self-acceptance, and a tendency to distance the self from involvement with others. Bartholomew (1990) believes that dismissing adults place great emphasis on being independent, at the expense of being emotionally intimate with 
attachment figures. The secure pattern (positive self/positive other), however, is characterized by feelings of high self-regard and self-acceptance, but they also place great importance on becoming emotionally intimate with attachment figures. The difference between these two patterns lies in their view of other people: Dismissing adults deny the need, possibly defensively, of close relationships, while secure adults place much emphasis on the emotional intimacy of close romantic relationships (Bartholomew, 1990; Bartholomew \& Horowitz, 1991). In the non-volitional separation from loved ones inherent in criminal incarceration, it seems likely that secure adults would react more strongly and more negatively to such separations than dismissing individuals. The safe haven of the attachment figure that secure adults turn to in times of stress is no longer available or accessible to them. Incarceration would likely be extremely distressing for them. Since they do not depend on others for support, dismissing adults tend to use their own internal resources when stressed, and hence, may be less likely to react as negatively or strongly to the prison environment. The most independent of the four attachment patterns, dismissing inmates will likely adjust the most positively to being separated from loved ones while imprisoned. Therefore, secure inmates may exhibit more depressive and anxious adjustment reactions as well as more disciplinary violations while incarcerated and separated from family and friends then dismissing adults, who deny the importance of attachment relationships.

Preoccupied adults (negative self/positive other) are characterized by a generally negative, unstable self-image which is dependent on and maintained through relationships with attachment figures. Since their sense of self is so dependent on feeling valued and 
needed within attachment relationships, it is likely that separations from important others while imprisoned would lead to significant and intense adjustment reactions characterized by elevated levels of anxiety and depression. Without others to validate themselves, such individuals already weak internal resources are likely to be depleted even more during such a separation. It is unclear how the preoccupied inmates will react to the reduced autonomy of the prison and whether they will react to such restrictions through rulebreaking and disciplinary problems. Because they tend to be quite hyper-vigilant to negative affect in the context of their attachment relationships, it is expected that imprisonment will likely lead to primarily aversive affective reactions rather than increased disciplinary violations because of the forced separation from loved ones they must endure. Overall, preoccupied individuals will likely have more serious levels of both affective reactions and disciplinary records when compared to secure and dismissing inmates, who both have positive views of the self and more adequate internal coping resources to handle the transition to prison.

Fearful adults (negative self/negative other) are generally characterized as having poor self-image, self-regard, and self-esteem in combination with an expectation that others are rejecting and untrustworthy. Across a variety of interpersonal and intrapersonal phenomena including self-acceptance, self-perceived competence, and relationship satisfaction, fearful individuals generally exhibit the most poorly developed skills and have the weakest internal resources and social supports of all of Bartholomew's patterns of attachment (Bylsma, et al., 1997; Pistole, 1995; Diehl, 1998). Since fearful adults do not have the internal resources to regulate internal distress or the external 
resources which allow them to turn to others for comfort and support, they have no reliable, secure places to look to during times of stress. Therefore, the perceived threat of the prison environment combined with the separation from attachment figures is likely to result in severe adjustment reactions from fearful inmates, both emotionally and behaviorally. Considering their deficits in stress management resources in conjunction with a variety of research results describing this group as having the most weaknesses of the four patterns of attachment, it is expected that fearfully attached inmates will exhibit the most difficulty adjusting to incarceration.

Overall, the research seems to indicate that attachment theory, and attachment patterns specifically, may help explain some of the individual differences inmates have adjusting to a prison environment. Attachment theory initially was based on the affective and behavioral reactions of infants separated from their primary caregivers. Based directly on Bowlby's (1969) work, Bartholomew (1990) proposed a theory of attachment in adults based on inner working models one has of the self and of others. This twodimensional model yields four distinct patterns of attachment which have been empirically validated in a number of follow-up studies and yield findings within a number of inter- and intra-personal domains consistent with both Bowlby's and Bartholomew's theories. What is missing in the adult attachment literature are studies examining the affective and behavioral reactions of adults separated from one's cherished attachment figures and placed in a stressful and ambiguous setting, studies which are the core of the infant attachment literature. Incarcerated adults face an undesired, unexpected, and uncertain separation from loved ones and are placed in a restricted, threatening prison 
environment. Such a separation should clearly elicit attachment behaviors in adults, behaviors which should vary according to one's attachment pattern and their concomitant inner working models. This study is a preliminary, exploratory step toward integrating the infant and the adult attachment literatures.

Even more importantly, this study may help identify why some adult inmates adjust to incarceration more negatively than other inmates. If the initial "transition shock" often observed in newly incarcerated inmates is found to vary by attachment style, this may have important practical implications for prison officials. For example, officials may have the impetus to change existing visiting policies so as to increase the availability of inmates' families, particularly in the first phase of their sentences. If certain attachment patterns appear to be associated with a more difficult adjustment reaction to prison, this may point out the need for particular intervention strategies for the prison's counseling and psychiatric departments. For example, one such supportive strategy may relate to helping the inmate cope with the separation from loved ones through group therapy with inmates facing similar difficulties. Family or marital counseling may also be indicated to ease the transition stress of the inmate at the beginning of his sentence. In light of the recent boom in prison populations, changes in visitation policies and focused therapeutic strategies may not only ease the period of adjustment shock for inmates, but also take some of the strain off the very limited mental health resources of the prison. Additionally, a less stressful initial transition for inmates could result in declines in rulebreaking and disciplinary infractions: Appropriate interventions, then, may also ease some of the burden of correctional officers charged with managing the disiuptive 
behavior of inmates.

\section{Research Question and Hypothesis}

Do incarcerated adults who have a secure or a dismissing attachment pattern according to the Bartholomew and Horowitz (1991) classification typology (as measured by the Relationship Questionnaire) adjust better to the prison environment both emotionally (as measured by selected BSI and MMPI-2 scales and the mental status interview scores) and behaviorally (as measured by the number and severity of recorded disciplinary violations) than incarcerated adults who exhibit a preoccupied or fearful attachment pattern?

It is hypothesized that adult attachment classification is related to the emotional adjustment to prison as measured by the brief mental status interview and select BSF and MMPI-2 scales. It is further hypothesized that the relationship is maintained in regard to behavioral adjustment to the prison environment as measured by the number and severity of disciplinary offenses since being incarcerated. Emanating from these hypotheses are the following predictions:

(1) Secure and dismissing adult prison inmates will exhibit lower levels of depression, anxiety, hostility, and global psychopathology as measured by the DEP, ANX, HOS, and GSI scales of the Brief Symptom Inventory than preoccupied and fearful adults;

(2) Secure and dismissing adult prison inmates will exhibit lower levels of depression, anxiety, anger, and poor self-esteem as measured by the DEP, ANX, ANG, and LSE Content Scales of the Minnesota Multiphasic Personality Inventory-2 than preoccupied or 
fearful adults;

(3) Secure and dismissing adult prison inmates will exhibit fewer symptoms of depression, anxiety, and anger, and higher levels of self-esteem according to a brief mental status interview than preoccupied or fearful adults;

(4) Secure and dismissing inmates will have fewer recorded disciplinary violations in their files than preoccupied or fearful adults; and

(5) Secure and dismissing inmates will have less severe, more benign disciplinary infractions in their files than preoccupied or fearful adults. 


\section{Method}

\section{Setting}

The study was carried out at the Adult Correctional Institute (ACI) in Cranston, Rhode Island, the only state prison within the state. Evaluations and measures were administered at the Intake Service Center (ISC), where inmates are held immediately following their sentencing and before their initial classification to an appropriate security level. Initial classification procedures and screening for educational and rehabilitative programs take place at the ISC, which is essentially a temporary housing center. Subjects were assessed in a small classroom within the ISC with 10 to 15 small desks and chairs. Pursuant to state law and Department of Corrections policy, inmates are to receive an educational and mental status screening evaluation within the first month of their sentence. Such evaluations are to be performed by a psychologist or advanced graduate students in psychology closely supervised by a psychologist. The current evaluation procedures have been in place since September 1996, and the author of this dissertation was involved in the design, collection, and interpretation of the above evaluations from their inception.

\section{Subjects}

The subjects for this study consist of 167 adult (18 years old or older) inmates who were referred for pre-classification screenings within two to four weeks of their sentencing, and who had been sentenced to at least a six month prison term. The mean age of inmates included in this study was 31.13 years (median of 30 and a range from 18 
to 62 years of age). The mean number of total criminal sentences resulting in incarceration for the sample was 2.62 (median of 2 with a range from 1 to 10 total incarcerations). In examining the racial breakdown of subjects in the sample, $50.9 \%$ (85) identified themselves as White, $29.9 \%(50)$ as Black, 9.6\% (16) as Hispanic/Latino, $4.2 \%$ (7) as Native American, 2.4\% (4) as Cape Verdian, 2.4\% (4) as "other," and $0.6 \%$ (1) as Asian. This is similar to the demographics of the overall population of the prison where approximately fifty percent of the current ISC population are Caucasian, 28 percent African-American, and 20 percent of Hispanic/Latino descent. Inmate samples generally have lower socio-economic status, poorer educational backgrounds, and more disruptive familial backgrounds compared to non-incarcerated samples. The average years of education of inmates included in the sample was 10.85 , which is less than the twelve years that would be required for graduation from a high school. Only $10.8 \%$ of subjects indicated that they were currently married, while $62.9 \%$ said that they had fathered at least one child. Approximately $84.4 \%$ of the sample spoke English as a first language, and another $13.8 \%$ indicated that they were bilingual. Approximately $90 \%$ of the sample was born in the United States, while the remainder hailed from Puerto Rico, the Dominican Republic, or elsewhere.

\section{Sampling Procedures and Calendar of Events for Data Collection}

Data were collected from October 1, 1998 until March 31, 1999 and gathered from inmate subjects within the first month of their sentence. Evaluations have been ongoing in the current format since September 1996, and were continued unchanged during the course of this study. Inmates are referred for pre-classification evaluations once they 
are formally sentenced and placed at the ISC. The total sample of 167 subjects consisted of inmates who were referred for the above evaluations during the time of the study, and who consented orally and in writing to participate in the present study. The sample of 167 inmates represents only a small proportion of the total population of male prisoners housed at the ISC during the time of the study. Most inmates did not participate in the prison's intake testing procedure because of limited testing staff and resources. Subjects not included in the study include inmates who did not or could not consent either orally or in writing to partake in this particular study and inmates who chose not to participate in the prison's assessment procedure and asked to return to their cell blocks. The sample assessed was convicted of a variety of crimes, but does not include inmates in protective custody who are judged by prison staff to be at risk if placed within the general inmate population. Female inmates are held at a separate facility at the ACI and were not included in the study.

\section{MEASURES}

\section{Attachment Measure}

Adult attachment pattern was assessed using Bartholomew and Horowitz's (1991) Relationship Questionnaire (RQ). The RQ is a self-report measure that consists of four paragraphs which describe in a few sentences the thoughts and feelings associated with the secure, preoccupied, dismissing, and fearful attachment patterns. Examples from each of the patterns: (1) "It is relatively easy for me to become emotionally close to others" (from the secure prototype); (2) "I want to be emotionally intimate with others, but I often find that others are reluctant to get as close as I would like" (from the preoccupied 
prototype); (3) "I am uncomfortable getting close to others" (from the fearful prototype); and (4) "I am comfortable without close emotional relationships" (from the dismissing prototype). Subjects are first asked to rate the applicability of each of the prototypes as it describes their experiences within close relationships on a seven point Likert scale, and then are to choose one of the four patterns which best describes their feelings about closeness and dependence within current significant relationships (see Appendix A).

Bartholomew and Horowitz's (1991) measure is an extension of the three category attachment measure developed by Hazan and Shaver (1987). This instrument has been widely used in the adult attachment literature, with results suggesting that its scores possess good reliability estimates and validities (Lyddon, Bradford, \& Nelson, 1993; Bradford \& Lyddon, 1994). A multi-item, continuous version of the four category model (The Relationship Scales Questionnaire or RSQ) was found to produce substantially the same results of those obtained using the categorical RQ (Griffin \& Bartholomew, 1994), suggesting the use of the simpler, more parsimonious instrument. Additionally, in a comparison of the continuous RSQ and the categorical RQ measure of attachment, factor analysis confirmed the two-dimensional, four category structure of the RQ, but did not support the dimensions hypothesized to underlie the RSQ (Siegert, Ward, Hudson, 1995; Carver, 1997). The RQ was developed to include the dismissing attachment pattern, which is characterized by positive feelings of self-worth combined with an expectation of others as being rejecting and untrustworthy. In a comparison of the three category measure and the RQ, the same two dimensions (model of self and model of other) hypothesized by Bartholomew (1990) were found to underlie both instruments. Subjects 
had similar responses across both, with only theoretically predicted differences between them (Shaver \& Hazan, 1993; Brennan et al., 1995).

Data from the RQ yielded a configuration consistent with Bartholomew's (1990) two-dimensional model of attachment using a non-metric multi-dimensional analysis. Correlations among the four attachment styles were patterned as predicted by the model. For example, there was a negative correlation between the preoccupied and dismissing attachment patterns $(-.37)$, as well as between the secure and fearful patterns $(-.65)$. Like the three category measure, the Bartholomew instrument has good face validity (Bradford \& Lyddon, 1994). Griffin and Bartholomew (1994) did extensive research on the convergent and discriminant validity of the self and other dimensions which underlie the RQ. Results from the RQ were statistically significantly correlated with interview and friend report ratings of attachment, and all three methods independently produced similar patternings of the attachment styles, providing some evidence of convergent validity (average coefficient of .38 , R-squared $=.15$ ). Studies of the discriminant validity of the self and other dimensions which underlie the RQ indicate that these dimensions are independent from each other (average coefficient of .09 , R-squared $=.01$ ). Finally, strong support was found for the construct validity and predictive validity of the RQ's self and other dimensions. For example, the positivity of an individual's reported self-model was highly correlated (.96) with the positivity of one's self-esteem, while the positivity of an individual's reported other model was highly correlated (.93) to the positivity of one's interpersonal orientation (Griffin \& Bartholomew, 1994). Additionally, the four attachment patterns have been shown to correlate in meaningful ways with certain 
personality constructs. For example, a fearful attachment pattern was positively correlated with neuroticism (.33) and negatively correlated with extraversion (-.23) and agreeableness $(-.26)$, while a secure attachment pattern was negatively correlated with neuroticism (-.30) and positively correlated with extraversion (.38), openness (.21), agreeableness (.17), and conscientiousness (.21) (Carver, 1997).

\section{Measures of Emotional Adjustment to Prison}

For the assessment of emotional adjustment to the prison environment, a licensed clinical psychologist and two advanced graduate students attempted to choose measures that were clinically relevant and had well established reliability and validity. Measures were approved by a prison review board, and had to be amenable to the wide-range of literacy skills prison populations typically exhibit. In addition, time constraints and the very structured prison environment dictated the necessity that measures be administered in a time efficient manner.

In adjusting to the prison environment, to separation from loved ones, or to any other stressful event, measures of anxiety and depression seem particularly relevant. In addition, levels of self-esteem and anger or hostility may be salient within a prison sample. Overall, then, the present research involved examining levels of internalized symptomatic behaviors and characteristics (e.g., depression, anxiety, self-esteem), as well as external, aggressive tendencies (e.g., anger/hostility) of inmates within the first few weeks of their sentences. The following measures were utilized to examine affective reactions to incarceration. Wherever possible, relevant constructs such as depression or anxiety were examined on more than one measure in an attempt to cross-validate results. 


\section{The Brief Symptom Inventory (BSI)}

The BSI is a 53 item self-report inventory of current psychopathology and stressors, and is not considered a direct measure of enduring personality (Derogatis, 1992). It is designed to assess and reflect point-in-time patterns of psychological symptoms of both psychiatric patients and non-patient respondents. Subjects are asked to endorse each item on a 5-point Likert scale, from 0 (not at all) to 4 (extremely), on how much each symptom has distressed or bothered them in the past seven days, including today. Based on its parent instrument the Symptom Checklist-90-R (Derogatis, 1977), the BSI yields scores on nine dimensions: (1) Somatization (SOM), (2) ObsessiveCompulsive (O-C), (3) Interpersonal Sensitivity (I-S), (4) Depression (DEP), (5) Anxiety (ANX), (6) Hostility (HOS), (7) Phobic Anxiety (PHOB), (8) Paranoid Ideation (PAR), and (9) Psychoticism (PSY). In addition to the main nine dimensions, the BSI also provides three global indices: the Global Severity Index (GSI), the Positive Symptom Total (PST), and the Positive Symptom Distress Index (PSDI). These three indices provide a more general assessment of current adjustment and functioning. The BSI items are written at a sixth grade level, and may be administered orally to subjects who are unable to read at this level. Typical item examples are: "How much were you distressed by:" "Feeling inferior to others?," "Thoughts of death or dying?," "Pains in heart or chest?," and "Having urges to break or smash things?"

The BSI manual (Derogatis, 1992) contains information relevant to the reliability, validity, and factor structure of the instrument. Derogatis reports internal consistency 
reliability estimates (via Cronbach's alphas) ranging from .71 on the PSY dimension to .85 on the DEP dimension. Independent researchers have found internal consistencies very similar to those found in the BSI manual (Broday \& Mason, 1991; Croog, Levine, Testa, Brown, Bulpitt, Jenkins, Klerman, \& Williams, 1986). Test-retest reliabilities over , a two week period range from .68 on the SOM dimension to .91 on the PHOB dimension. The Global Severity Index had a stability coefficient of .90, demonstrating acceptable consistency over the two-week interval.

The manual focuses primarily on the construct validity and internal structure of the BSI. In correlations with the MMPI, good convergent and concurrent validity was demonstrated between similar scales of the two measures, though the discriminant validity of some of the dimensions was less impressive. The manual also describes factor analytic studies of the BSI. According to reviews in the Tenth Mental Measurements Yearbook (1989), "The results confirmed to a remarkable degree the a priori construction of the symptom dimensions (p. 111)," and, "factor analytic results demonstrate impressive agreement between the factor structure and the a priori dimensional structure (of the BSI) (p. 112)." Although there were some minor divergences evident in the factor analysis, it appears that the BSI demonstrates evidence of acceptable construct validity. The manual also describes numerous studies relevant to establishing the initial predictive validity of the BSI.

While the nine symptom dimensions and the three global indices were statistically analyzed to examine patterns of psychological symptoms, four scores in particular were used in the present study's operational definition of prison adjustment. Because 
depression, anxiety, and hostility have all been shown to be germane in prior studies of prison adjustment, the BSI symptom dimensions of DEP, ANX, and HOS were used in the main analysis. In addition, several authors have suggested that the GSI (Global Severity Index) score of the BSI is a valid measure of current psychological distress (Boulet \& Ross, 1997; Piersma, Boes, \& Reaume, 1994; Piersma, Reaume, \& Boes, 1994). For this reason, the GSI score was also used in this study as an indicator of current emotional adjustment.

\section{Minnesota Multiphasic Personality Inventory-2 (MMPI-2)}

The 567 item MMPI-2 is a self-report assessment measure of psychopathology and personality (Butcher, Dahlstrom, Graham, Tellegen, \& Kaemer, 1989). According to reviews in the $11^{\text {th }}$ Mental Measurements Yearbook (1992), "The revision (of the MMPIII) breathes new life into a test the utility and excellence of which have made it to the most widely used device for personality measurement in the world (p. 565)." The measure yields scores on validity, clinical, and supplemental scales, similar to the original MMPI. In addition, 15 content scales were developed for the MMPI-2 based on the content of items already present in the original MMPI. Because the clinical scales are of limited utility in lieu of their heterogeneous item content, only the more homogenous content scales ( DEP, ANX, ANG, and LSE) were considered in the present study. Using a combination of rational and statistical methods, Butcher, Graham, Williams, and BenPorath (1990), the 15 MMPI-2 content scales were developed using a multi-stage, multimethod approach. Their method is described in detail in Butcher et al. (1990), but included (1) the rational identification of content areas, (2) the statistical deletion and 
addition of items to scales, (3) a final rational review of items, (4) a final statistical refinement of items, and (5) a rational description of each of the 15 resultant scales.

According to Butcher et al. (1990), the 15 Content Scales can be grouped into four general clinical areas. Those general clinical areas are (1) Internalized Symptomatic Behaviors (including Anxiety (ANX), Fears (FRS), Obsessiveness (OBS), Depression (DEP), Health Concerns (HEA), and Bizarre Mentation (BIZ) content scales), (2) External Aggressive Tendencies (the Anger (ANG), Cynicism (CYN), Antisocial Practices (ASP), and Type A Behavior (TPA) content scales), (3)Negative Self-Views (the Low Self-Esteem (LSE) content scale), and (4) General Problem Areas (the Family Problems (FAM), Social Discomfort (SOD), Work Interference (WRK), and Negative Treatment Indicators (TRT) content scales).

Butcher et al. (1990) include both internal consistency and test-retest reliability data for the content scales. Internal consistency as measured by Cronbach's alphas range from a low of .68 for the TPA scale to a high of .86 for the DEP and CYN scales in a normative sample. They also provide internal consistency alphas for psychiatric, alcoholic, and military samples. They note that the internal consistencies are well within an acceptable range in all four samples, suggesting that items within each content scale display a good degree of homogeneity. In reviewing the content scales of the MMPI-II, the $11^{\text {th }}$ Mental Measurements Yearbook suggests that, "An internally consistent anxiety scale to stand beside an internally consistent depression scale has been needed for years (p. 564)." Test-retest reliabilities range from a low of .78 for the BIZ scale to a high of .91 for the WRK scale. The average retest interval for the sample was nine days. Other 
researchers have found similar retest coefficients over a four month (Putnam, Kurtz, \& Houts, 1996) as well as over a five year period (Spiro, Butcher, Levenson, Aldwin, \& Bosse, 1993) for the MMPI-2 content scales.

In the validity studies provided in Butcher et al. (1990), they describe correlations for each content scale with both other MMPI- 2 measures as well as behavioral correlates as external sources of validity. The behavioral data was obtained from couples providing information as part of the MMPI-2 re-standardization project, and is explained in detail in Butcher et al. These results provide preliminary support for the validity of the MMPI-2 content scales. Independent studies since the MMPI-2 was published have suggested that the Content Scales have incremental validity above the clinical and supplementary scales of the original MMPI in the assessment of psychopathology, treatment outcome, and styles of coping (see Chisholm, Crowther, \& Ben-Porath, 1997; Endler, Parker, \& Butcher, 1993; Ben-Porath, McCully, \& Almagor, 1993; Ben-Porath, Butcher, \& Graham, 1991).

Since the primary purpose of this study is individual differences in prison adjustment, not all the content scales were relevant to this construct. As described earlier, areas of depression, anxiety anger, and self-esteem have been important indicators of emotional adjustment of inmates in past research. Hence, the ANX, DEP, ANG, and LSE content scales were the main focus in the primary analysis. Strassberg (1997) examined the concurrent validity of these four content scales in particular, and found strong evidence that the ANX, DEP, ANG, and LSE scales measure what they are intended to measure in samples of American and Australian college students. Specifically, DEP 
scores were correlated with Beck Depression Inventory scores, ANX scores were correlated with State-Trait Anxiety Inventory scores, LSE scores were correlated with Self-Esteem Inventory scores, and ANG scores were correlated with State-Trait Anger Expression Inventory scores, all of them correlating significantly. In addition, they found that these four content scales were more highly correlated with the appropriate criterion measure than were the traditional MMPI-2 validity and clinical scales.

Other studies have examined the validity of the scores on these four content scales as well. Clark (1994) found that scores on the ANG content scale were statistically significantly correlated with other measures of anger in a chronic pain sample. Boone (1994) found that the DEP content scale correlated highly with other measures of depression. The DEP, ANX, and ANG scales have been found to correlate meaningfully with measures of the big five personality dimensions (Quereshi \& Kleman, 1996). Factor analytic studies of the DEP and ANX scales suggest that these scales measure latent variable conceptually related to depression and anxiety, respectively (Ward, 1997). Similarly, the LSE content scale was shown to have good internal consistency and to be highly correlated with the Harter Adult Self-Perception Profile and the Rosenberg SelfEsteem Scale (Brams \& Lloyd, 1995). Overall, then, the DEP, ANX, ANG, and LSE scales appear to be reliable and valid measures of their intended constructs, and were used in this study as measures of emotional adjustment.

\section{Brief Mental/Affective Status Interview}

In addition to the administration of the MMPI-2 and the BSI, each inmate has undergone a one-on-one interview with either a trained graduate student or a licensed 
psychologist. Much of the interview focuses on ascertaining an inmate's basic demographic information, court and institutional records, substance abuse history, educational level, counseling history, medical history, and family background. In addition, there is a brief screening of mental and affective status designed to assess four psychological domains: (1) depressive prison adjustment reactions, (2) anxious adjustment reactions, (3) hostile/angry reactions, and (4) current feelings of self-esteem. For all four of these areas, inmates were encouraged to describe their current feelings since they have been incarcerated.

The depression screening consists of the following items, to which an inmate was verbally asked to respond via yes or no answers as to whether they were currently experiencing: (1) feelings of sadness, (2) feelings of hopelessness, (3) feelings of worthlessness, (4) feelings of loneliness, (5) loss or diminished appetite, (6) sleep difficulties, (7) lowered energy levels, and (8) suicidal ideation. The number of yes responses was totaled to create a 'depression score.' The highest possible score is eight (all 8 symptoms endorsed), while the lowest possible score is zero (no symptoms endorsed). The anxiety screening asked inmates if they are currently experiencing: (1) feelings of nervousness, (2) feelings of being tense, (3) irritability, (4) feelings of being afraid or fearful of something, and (5) presence of panic attacks. Again, scores were totaled to create an 'anxiety score,' with a high score of five symptoms endorsed and a low score of zero with no symptoms endorsed. The anger or hostility screening asked inmates to rate their current feelings of anger on a scale one (currently feeling no anger) to ten (feeling extremely angry at present). Finally, a self-esteem question, which is 
embedded within the depression screening, was posed which asked inmates to rate their current level of self-esteem on a scale of one (extremely low) to ten (very high). The mental status screening was devised by using symptoms described within the Diagnostic and Statistical Manual of Mental Disorders, Fourth Edition specifically for use with inmates at the ACI. Hence, no reliability or validity data are available for the mental status interview and no data on inter-rater reliability exists. Inmate responses to this brief screening were used as an additional measure of depression, anxiety, anger, and selfesteem in conjunction with the relevant BSI and MMPI-2 scales (see Appendix B for mental status interview).

\section{Measure of Behavioral Adjustment}

Much of the prison adjustment literature uses disciplinary violations as a measure of mal-adaptation while incarcerated without including measures of emotional adjustment. Since the safe and efficient management of inmates is a primary concern of institutional staff, the disciplinary records of inmates were used here as a measure of prison adjustment as well. Also, the measures of emotional adjustment described above rely on the self-report of inmates, while disciplinary records are a well-documented, independent measure of behavioral adjustment.

The disciplinary records of inmates were used as a measure of prison adjustment in two distinct ways. First, the number of disciplinary infractions as obtained from institutional files of inmates was examined. For each inmate at the ACI, a carefully documented record of rule violations is kept from the date that they are committed to the Intake Service Center. Since the focus of this study is the initial transition phase of 
incarceration, the number of violations of each subject was counted for the first three months from their date of commitment to the institution and analyzed via attachment patterns.

As a second distinct measure of behavioral adjustment, the severity or type of recorded disciplinary violations was examined. A classification officer from the $\mathrm{ACI}$, a psychologist, and two advanced graduate students examined the different types of violations inmates could be cited for and developed a five-category taxonomy based on the severity of the infraction from the point-of-view of prison management and safety to correctional officers and other inmates. The level one offense, deemed the most severe type of infraction, was escaping or attempting to escape from the prison. Level two offenses, labeled 'assaultive behaviors,' included such offenses as committing an assault and/or battery against an inmate or correctional officer, inciting a riot, hostage taking, aggressive, non-consensual sexual misconduct, and fighting. Level three offenses, labeled 'threatening behaviors,' included extortion of any inmate or correctional officer, possession of a weapon, and making verbal or written threats to others. Level four offenses, labeled 'defiance of institutional structure,' included a wide range of offenses relating to open defiance of correctional officers or involved the deception of prison staff. Offenses at level four include such things as hiding, refusal to work, failure to report to required destinations, fraudulent requests, giving false information to correctional staff, and refusal to comply with count procedures, among others. Finally, level five offenses, labeled 'volitional infractions,' were deemed the least severe disciplinary violations. These offenses caused minimal difficulty for prison staff and generally involved 
behaviors that affect only the offending inmate. Offenses at level five include being intoxicated, volitional sexual misconduct, possession of unauthorized currency, tattooing oneself or others, gambling, wearing gang colors, and making unauthorized phone calls, among others (see Appendix C for the severity classification scheme). Severity of disciplinary violations was examined by giving a point value to each recorded offense in an inmates files. Level one offenses were given five points, level two offenses were given four points, level three offenses three points, level four offenses two points, and level five offenses one point. Points were totaled for each violation within an inmate's file and then divided by the total number of violations to create a severity index or average for the recorded rule infractions.

\section{Procedure}

The following evaluation and assessment was designed by a licensed psychologist and the prison classification board to satisfy the minimum requirements of Rhode Island state laws relating to the psychiatric and educational screening of inmates upon intake into the ACI. The standard evaluation procedure consists of (1) an assessment of current mental status, substance abuse history and mental health treatment history, as well as familial, criminal, educational, and medical background in interview form, (2) assessment of current mental status via the Brief Symptom Inventory (available in English and Spanish, and presented orally to inmates whenever necessary), (3) assessment of current functional literacy in English or Spanish using an individually administered measure of cognitive-academic language proficiency (CALP), the Woodcock-Munoz Language Survey (which was a measure NOT utilized in the study), and (4) administration of the 
MMPI-2, available in English or Spanish, in booklet or audiotape format as needed. Inmates who read and speak primarily Spanish were excluded from participation in the study. This information is gathered so that a pre-classification report for each inmate can be forwarded to the classification board. The classification board forwards this report upon receipt to the facility to which the inmate has been classified. There it is placed in the inmate's file, where it is referred to in case the inmate is interested in counseling or educational services in the future.

Inmates were assessed in approximately two or three weekly sessions, with four to seven inmates tested per session. All testing was completed within one session, lasting on average three and one-half hours. Measures were administered by advanced graduate student assistants under the supervision of a licensed psychologist.

At the beginning of each testing session, the inmates were given an explanation of the purposes of the pre-classification evaluation, its format, and its expected length. The graduate students introduced themselves at this point, and asked if there were any questions at that time. Once questions had been answered, the inmates were given a packet containing the MMPI-2 question booklet and scantron sheet. The instructions for the MMPI-2 were given, and inmates were asked if they would like a Spanish MMPI-2 booklet, or if they prefer to listen to the MMPI-2 via audiotape. They were then told that as they completed the MMPI-2, they would be called to come up to the front of the room so that they could complete additional measures on a one-on-one basis with test administrators.

During the individual testing, inmates first were administered the mental status 
and background history interview by an experimenter. Once this was completed, the Woodcock-Munoz Language Survey was administered. Next, the BSI was explained to the inmate in detail and completed. After the completion of the BSI, inmates were asked individually for their consent to allow the evaluating team to look into their institutional records at a later date in order to obtain recorded data concerning their prison adjustment, particularly information related to disciplinary violations. The research was described orally as a study examining the effects of one's views of social relationships and how this view may relate to how one adjusts to the prison environment. Inmates were told that their results would be averaged in with scores from other inmates, and that they would not be identified personally in future publications or in discussions of relevant findings. In addition, it was strongly emphasized that participation was completely voluntary and was in no way mandatory. They were told that participation would not benefit them individually in any way, and that declining to participate would not hurt them in any way. They were also told that they could choose to withdraw from the study at any time without any penalty to them. Questions were fielded from inmates at this point. After the study was explained orally, a consent form was given to each inmate, which they were asked to read over carefully. The test administrator asked the inmates if they had any questions or if they would like the consent form to be read to them orally. Each inmate then signed the consent form and checked either a consent or do not consent box. A copy of the consent form was given to each inmate. Then each was given the Relationship Questionnaire (RQ) measure of attachment to complete if he had consented to participate in the project. Once this was completed, the inmate was asked to return to his desk to 
complete the MMPI-2.

This procedure was followed throughout the testing session until all inmates had completed the individually administered measures, had the research project explained to them, and finished responding to the MMPI-2. Inmates were then thanked for their time and cooperation and permitted to return to their appropriate cell block upon completion of the MMPI-2.

Assessment instruments were scored in the following ways: the RQ, BSI, and mental status scales were scored individually by the experimenter, and the MMPI-II was sent to the NCS Corporation for computer scoring.

\section{Method of Data Analysis}

Prior to the statistical analysis, the data were examined and any necessary corrections were made for outliers or missing information. There were no missing data relating to the independent (e.g., attachment patterns) or the dependent variables of interest (e.g., MMPI-II, BSI, mental status, or disciplinary scores). There were a few demographic pieces of information not attained for all of the 167 subject sample. In all cases, there was no more than one subject's information for any one demographic variable missing. Since the missing information would have negligible effects on the demographic description of the sample, this was not corrected in the demographics described in the study. The analyses were conducted in the following steps:

(1) Four one-way analyses of variance were conducted to examine the relationship among attachment patterns and scores on the DEP, ANX, ANG, and LSE Content Scales of the MMPI-2. The independent variable, attachment pattern, has four levels; secure, 
dismissing, preoccupied, and fearful attachment. The dependent variable is scores on the select MMPI-2 scales, each with a mean standard score of 50 and a standard deviation of ten. The Tukey test was used to assess which of the attachment patterns' means differed from one another for each of these four ANOVAs, assuming post hoc testing was necessary. The Tukey test was selected because it is a more moderate post hoc test as compared to more liberal tests such as Fisher's LSD and more conservative tests such as Scheffe. Effect sizes via R-Squared were calculated for each significant ANOVA to determine how much of the total group variance could be accounted for by the attachment patterns.

(2) Four one-way ANOVAs were conducted to examine the relationship among attachment patterns (the independent variable) and scores on the DEP, ANX, HOS, and GSI scales of the BSI (the dependent variable). Each BSI scale has a mean standard score of 50 and a standard deviation of ten. When necessary, Tukey post hoc tests and effect sizes were computed to compare the means on the attachment patterns on these scales.

(3) Four one-way ANOVAs were conducted to examine the relationship among attachment patterns and scores on depression, anxiety, anger, and self-esteem from the mental status interview. Tukey post hoc tests and effect sizes were computed when necessary.

(4) Two one-way ANOVAs were conducted to examine the relationship among attachment patterns and the mean number as well as the mean severity rating of recorded disciplinary violations. Tukey post hoc tests and effect sizes were computed when 
necessary.

Please note that all ANOVAs in the study were computed using SPSS 7.5 for Windows. This statistical package uses algorithms consistent with the general linear hypothesis in computing ANOVAs, and was used in all such analyses. The program used within SPSS was the General Linear Model - General Factorial.

(5) To identify relevant prison adjustment variables that are able to distinguish the secure, dismissing, preoccupied, and fearful attachment patterns, an exploratory descriptive multiple discriminant function analysis was conducted to determine if six predictors DEP, ANX, HOS, and GSI from the BSI, and the number and severity of disciplinary violations - could separate the four attachment patterns.

(6) A separate exploratory descriptive multiple discriminant function analysis was conducted to determine if another set of six predictors - the DEP, ANX, ANG, and LSE from the MMPI-2, as well as the number and severity of disciplinary violations - could distinguish the four patterns of attachment. Only two discriminant analyses were conducted so that a sufficient ratio of subjects to predictors (approximately 15-20 subjects per variable) was available.

Please note that all discriminant analyses were computed with SPSS 7.5 for Windows using the Classify-Discriminant program.

\section{Resources that were required}

This research required the following assessment devices: The Relationship Questionnaire, The Minnesota Multiphasic Personality Inventory-2, The Brief Symptom Inventory, and a brief mental status interview. All of these instruments were already in 
use within the prison before this study began and have been paid for and approved for use with male inmates by the Adult Correctional Institute in Cranston, Rhode Island. Scoring of the MMPI-2 protocols took place in Minnesota and was funded through a grant between the ACI and the NCS Corporation.

Computer equipment was required for the logging and analysis of data, which was also provided for this project by the ACI. Inmate files were also necessary to gather information of the disciplinary history of subjects, and access to such files had been granted by the ACI.

Finally, criminal background checks and security clearance were necessary for the experimenter and any other administrators of the above tests. The experimenter had clearance to work with the inmate population of the ACI for the duration of the study. 


\section{Results}

In preliminary analyses, $31.7 \%(53)$ of the 167 inmates endorsed the secure attachment style as characterizing them, 9.6\% (16) endorsed the preoccupied style, $24 \%$ (40) endorsed the dismissing style, and $34.7 \%$ (58) endorsed the fearful style. The distribution of the attachment patterns is different from those obtained by other researchers (Bartholomew \& Horowitz, 1991; Bylsma, Cozzarelli, \& Sumner, 1997) in that the most prevalent pattern was the fearful rather than the secure style. Preliminary Chi-Square and ANOVA analyses revealed no statistically significant differences related to age, years of education, ethnicity, type of crime committed, or marital status within the four-category classification system.

\section{Tests of Main Hypotheses - Analysis of Variance}

To evaluate the relationship between attachment pattern and the emotional and behavioral adjustment to the prison environment, 14 separate one-way analyses of variance (ANOVAs) were conducted. The primary hypotheses predicted that inmates who endorsed the secure and dismissing attachment patterns would adjust better to the prison environment both emotionally (as measured by specific MMPI-2 and BSI scales as well as scores from a mental status interview) and behaviorally (as measured by the number and severity of recorded disciplinary violations while imprisoned) than inmates who endorsed a preoccupied or fearful attachment pattern.

Table 1 presents the mean scores on the MMPI-2 Low Self-Esteem (LSE), Anger (ANG), Anxiety (ANX), and Depression (DEP) Content Scales for each attachment pattern, along with the F-ratio, significance level, R-Squared, and Tukey post hoc tests 
from each of the ANOVAs.

\section{Insert Table 1 about here}

The results from the omnibus F-tests in Table 1 indicate that there are statistically significant differences at the .05 level among the attachment patterns on each of the four MMPI-2 Content Scales of interest. The Tukey test was used to evaluate pairwise differences among the means. Examining the LSE scale, which is a measure of poor selfesteem, the post hoc test indicated that the secure inmates' mean score was different from both the preoccupied and fearful inmates. The secure inmates had fewer difficulties with low self-esteem than the preoccupied and fearful inmates on the LSE scale. The dismissing inmates did not differ from either the preoccupied or fearful inmates on the LSE scale. The effect size measured by R-square is a useful way of determining the practical significance of a particular statistical finding (Thompson, 2002). The R-square from the overall ANOVA on the LSE scale is .11, indicating that 11 percent of the variance in the LSE scores can be accounted for by the attachment patterns. According to the typology described in Green, Salkind, and Akey (1997), "Traditionally, R-squared values of $.01, .06$, and .14 represent small, medium, and large effect sizes, respectively (p. 193)." Therefore, on the LSE scale the practical significance of the result is in the medium effect range.

On both the ANX (an indicator of elevated levels of anxiety) and DEP (an elevated depression indicator) scales, the post hoc testing indicated that secure inmates' mean scores were different from both the preoccupied and the fearful inmates. The secure inmates' levels of anxiety and depression are lower than those of the preoccupied 
and fearful inmates on these scales. The Tukey test also detected that dismissing inmates' mean scores were different on the ANX and the DEP scales from the fearful inmates, and that they did not differ from the preoccupied inmates on these scales. Dismissing inmates had lower levels of anxiety and depression than the fearful inmates, but not the preoccupied inmates. In examining the practical significance of these results, the RSquared for the ANX analysis indicated that 16 percent of the variance was accounted for by the attachment patterns indicating a moderately large effect size. The R-Squared for the DEP analysis indicated that 18 percent of the variance was accounted for by the attachment patterns which is also in the moderately large effect size.

Finally, on the ANG (an indicator of elevated feelings of anger) scale, post hoc tests indicate that secure inmates had different mean scores than the fearful inmates, but not preoccupied inmates. Secure inmates had lower anger levels than fearful inmates but not the preoccupied inmates on this scale. Dismissing inmates did not differ from either preoccupied or fearful inmates on the ANG scale. The R-Squared in the ANG analysis indicated that 10 percent of the variance was accounted for by the attachment patterns which is a medium effect size.

In total, the results from the ANOVAs on the four MMPI-2 Content Scales partially support the study's predictions. While the omnibus F-tests indicated a statistically significant difference at the .05 level on all four of these scales, post hoc analyses did not detect differences between both the secure and dismissing inmates and both the preoccupied and fearful inmates on the ANX, DEP, ANG, and LSE scales. However, according to post hoc analyses, secure inmates had lower scores than fearful 
inmates on all four scales, and lower scores than preoccupied inmates on three of the four scales (with the exception of ANG). In addition, dismissing inmates had lower scores than fearful inmates on the ANX and DEP scales, but there was no difference among these groups on the LSE or ANG scales. Post hoc analyses indicated no differences between fearful and preoccupied inmates, nor between secure and dismissing inmates, on any of the MMPI-2 scales. Moderately large effect sizes were found in the analyses of the ANX and DEP scales and medium effect sizes were found in the analyses of the LSE and ANG scales, suggesting these results have some practical significance.

Table 2 presents the means and relevant statistics relating to the four ANOVAs for the Hostility (HOS), Anxiety (ANX), Depression (DEP), and Global Severity Index (GSI) scales of the Brief Symptom Inventory (BSI).

\section{Insert Table 2 about here}

The results of the omnibus F-tests in Table 2 indicate that there are statistically significant differences at the .05 level among the attachment patterns on each of the four BSI scales of interest. According to post hoc analyses on the HOS (indicator of increased hostile feelings) scale, secure inmates had different scores than both the preoccupied and fearful inmates. Secure inmates had less feelings of hostility than either preoccupied or fearful inmates. Dismissing inmates did not differ on the HOS scale from these latter two groups according to the Tukey test. In examining the practical significance of this analysis, ten percent of the variance was accounted for by the attachment patterns, a medium effect size.

On the DEP (indicator of feelings and symptoms of depression), ANX (indicator 
of anxious feelings and symptoms), and GSI (indicator of overall global psychological distress) scales, post hoc analyses indicate that both secure and dismissing inmates had different mean scores than both the preoccupied and the fearful inmates. Here, both secure and dismissing inmates had lower levels of depression, anxiety, and global psychopathology than both preoccupied and fearful inmates. There was a moderately large effect size for the GSI and ANX scales with 18 percent and 14 percent of the variance accounted for by the attachment patterns in the analyses, respectively. The analysis of the DEP scale from the BSI indicated a medium effect size with 12 percent of the variance accounted for by the attachment patterns.

Overall, only the HOS scale from the BSI did not confirm the study's predictions in that dismissing inmates did not have different scores than preoccupied and fearful inmates. The effect size for this scale was only in the medium range. The results from analyses of the DEP, ANX, and GSI scales are fully consistent with the study's predictions. In these analyses, both ANX and DEP had moderately large effect sizes while the ANX scale was in medium effect size range, suggesting that there is practical significance to these results.

Finally, Table 3 presents the means and relevant statistics for the four ANOVAs relating to scores from the one-on-one mental status interview: (1) depression score (DEP), (2) anxiety score (ANX), (3) anger score (ANG), and (4) self-reported self-esteem (S-EST). Table 3 also includes the statistics for the two ANOVAs relating to behavioral adjustment: mean number of disciplinary bookings while imprisoned (\#DISC) and mean severity ranking of disciplinary bookings while imprisoned (SevDisc). 


\section{Insert Table 3 about here}

Examining Table 3, only the omnibus F-tests for the depression, anxiety, and selfesteem scores from the mental status interview were statistically significant at the .05 level. For both the depression and anxiety scores from the mental status interview, post hoc analyses indicated that secure inmates had different scores than both preoccupied and fearful inmates. Secure inmates had lower levels of depression and anxiety than fearful and preoccupied inmates. Dismissing inmates did not differ from either the fearful or preoccupied inmates on the depression and anxiety scores as indicated by the Tukey test. In these analyses, medium effect sizes were evident in that attachment patterns accounted for 9 percent of the variance in the depression score and 8 percent of the variance in the anxiety score.

Though the overall F-test for the self-reported self-esteem score indicated a statistically significant difference at the .05 level, the Tukey test did not indicate where the differences lie among the attachment patterns. Examining the mean scores in Table 3, secure inmates had the highest mean self-reported self-esteem score ( 7.70 out of 10$)$, followed by dismissing inmates (7.43), then fearful (6.65), and finally preoccupied (6.06) inmates. Only seven percent of the variance in the self-esteem score was accounted for by the attachment patterns, a medium effect size. The ANOVA on the last score from the mental status interview, self-reported anger, indicated no statistically significant difference at the .05 level among the attachment patterns. Only four percent of the variance in the anger score was accounted for by the attachment patterns, a small effect size. 
On the two measures of behavioral adjustment, no statistically significant difference at the .05 level among the four attachment patterns emerged. In examining the mean number of recorded disciplinary bookings while imprisoned (displayed in Table 3), dismissing inmates had a mean of 2.73 bookings, followed by secure ( 3.13$)$, fearful (3.98), and finally preoccupied (5.56) inmates. Only 2 percent of the variance was accounted for in the number of bookings by attachment pattern, a small effect size suggesting limited practical significance. In examining severity rating mean scores, dismissing inmates had a 5.48 mean severity ranking, followed by secure (6.13), fearful (8.02), and finally preoccupied (11.63) inmates. Only 3 percent of the variance could be accounted for by the attachment patterns in the severity ranking, a small effect size.

In summary, the study's predictions were that secure inmates and dismissing inmates would have lower scores (indicating fewer difficulties) than both preoccupied and fearful inmates on the emotional and behavioral indicators of adjustment. These results only partially support those predictions. In total, 14 ANOVAs were conducted to test these predictions. Eleven of these fourteen analyses indicated that there were statistically significant differences at the .05 level among the attachment patterns. There were no differences among the attachment patterns on the anger score from the mental status interview or on either of the measure of behavioral adjustment (number and severity of disciplinary violations). There were statistically significant differences at the .05 level on the four scales from the BSI, the four scales from the MMPI-2, and on three of the four scales from the mental status interview.

Post hoc tests indicated that secure inmates had lower scores than fearful inmates 
on ten of the 14 indicators of adjustment (the MMPI-II scales of DEP, ANX, LSE, and ANG; the BSI scales of HOS, DEP, ANX, and GSI; and the DEP and ANX scores from the mental status interview). Secure inmates had lower scores than preoccupied inmates on nine of the 14 indicators of adjustment (the MMPI-II scales of DEP, ANX, and LSE, the BSI scales of HOS, DEP, ANX, and GSI, and the DEP and ANX scores from the mental status interview). Results were more mixed for the dismissing inmates. According to post hoc analyses, these inmates had lower scores than fearful inmates on five of the 14 indicators of adjustment (the MMPI-II scales of DEP and ANX, and the BSI scales of DEP, ANX, and GSI). Dismissing inmates had lower scores than preoccupied inmates on only three of the 14 indicators of adjustment (the BSI scales of DEP, ANX, and GSI). In total, secure and dismissing inmates had lower scores than both fearful and preoccupied inmates on three of the 14 indicators of adjustment (the BSI scales of DEP, ANX, and GSI). Additionally, none of these analyses indicated that fearful or preoccupied inmates exhibited better levels of adjustment than secure or dismissing inmates. As expected, on all 14 of the dependent measures, there was no statistically significant difference at the .05 level between secure and dismissing inmates, nor between preoccupied and fearful inmates.

\section{Exploratory Multiple Discriminant Function Analyses}

Multiple discriminant function analyses (MDFAs) were conducted to explore if two separate sets of predictors could distinguish the four patterns of attachment. In the first analysis, six predictors were used: MMPI-2 Content Scales DEP, ANX, ANG, and LSE, along with the number and severity of recorded disciplinary violations while 
imprisoned. The overall Wilks Lamba was statistically significant at the .05 level, Lambda $=.75$, Chi-Square $(18, N=167)=45.86, p<.001$, indicating that overall the predictors differentiated among the four attachment patterns. The residual Wilks Lambda was not statistically significant at the .05 level.

The following interpretation of this discriminant function is problematic, however, because an assumption of MDFA appears to have been violated. One of the assumptions of MDFA is that the population variances and covariances among the attachment patterns (the dependent or grouping variable) are the same for the secure, dismissing, fearful, and preoccupied groups. This assumption of the homogeneity of the variance-covariance matrices was assessed using the Box' $M$ statistic and the results of this test suggest that this assumption was not met. Because of this, the validity of this MDFA is questionable, and the following results should be interpreted with great caution. The interpretation of the function will still be included despite this violation only because the discriminant analyses are exploratory in nature and are not related specifically to the study's predictions.

In Table 4, the within-group correlations between the predictors and the discriminant function are presented, along with the standardized coefficients. Green et al. (1997) describe using this data to interpret the discriminant function by "examining the magnitudes of the standardized coefficients for the independent variables in the function and the correlation coefficients between the independent variables and the function within groups (p. 336)." This method will be used to interpret the discriminant functions as well. 


\section{Insert Table 4 about here}

For the significant function, MMPI-2 Content Scales DEP and ANX have relatively large coefficients and standardized weights. Other scales included in the analysis, including ANG and the behavioral indicators of number and severity of disciplinary violations, had relatively small coefficients and standardized coefficients in comparison. These more "behavioral" or "acting out" predictors did not add meaningfully to the analysis. Based on these results, this function appears to represent a subjective, internalized distress dimension.

Table 5 presents the unstandardized canonical discriminant function at the group mean or the group centroids for each of the attachment patterns. Green et al. (1997) describe using this data to determine which level(s) of the grouping variable (in this case the four different attachment patterns) is associated with the discriminant function. This method was used to further interpret the function.

\section{Insert Table 5 about here}

Both preoccupied and fearful inmates tend to score higher on this internalized distress dimension than either secure or dismissing inmates. It appears inmates with depressive or anxious symptomology are more likely to have a fearful or a preoccupied attachment pattern, and less likely to have a secure or a dismissing attachment pattern, than inmates without such internalized, subjective distress. Recall, however that this exploratory result must to be taken with caution because the homogeneity of the variance-covariance matrices assumption was violated. This may seriously affect the validity of the result and should be taken into consideration when gauging the practical significance of the result. 
In the second multivariate discriminant analysis, six predictors were used: the HOS, DEP, ANX, and GSI scales from the Brief Symptom Inventory, along with the number and severity of recorded disciplinary violations while imprisoned. The overall Wilks Lambda was statistically significant at the .05 level, Lambda $=.76$, Chi-Square $(18$, $167)=44.39, \mathrm{p}<.001$, indicating that overall the predictors differentiated among the four attachment patterns. The residual Wilks Lambda was not statistically significant. Again, according to the Box's M statistic, the homogeneity of the variance-covariance assumption was violated, which seriously threatens the validity of this discriminant analysis. The following interpretation of the function was included only because it is exploratory in nature and does not relate specifically to the study's predictions.

In Table 6, the within-group correlations between the predictors and the discriminant function are presented, along with the standardized weights.

\section{Insert Table 6 about here}

For the significant function, BSI scale GSI (global severity index) has a relatively large coefficient and standardized weight compared to the other BSI scales and the behavioral adjustment variables. Based on this, this function may represent an overall psychological distress or maladjustment dimension.

Table 7 presents the unstandardized canonical discriminant function at the group mean for each of the attachment patterns.

\section{Insert Table 7 about here}

Both preoccupied and fearful inmates tend to have higher scores on this overall psychological maladjustment dimension than either secure or dismissing inmates. It 
appears inmates with greater overall psychological distress are more likely to have a fearful or a preoccupied attachment pattern, and less likely to exhibit a secure or a dismissing attachment pattern, than inmates without such overall distress.

Again, this interpretation is problematic because the Box's M test indicates that the homogeneity of the variance-covariance matrices assumption was violated. Because this assumption was not met, the above analysis could be invalid, and hence, its results and practical significance need to be interpreted with caution.

Overall, the validity of the results from the MDFAs is questionable because a basic assumption of these analyses was violated. With this caveat, the exploratory MDFAs conducted on the two sets of predictors suggest that these predictors may be able to differentiate between the Secure and Dismissing groups and the Fearful and Preoccupied groups. Using the four MMPI-2 Content scales and the two behavioral adjustment variables, the first discriminant analysis was able to separate fearful and preoccupied inmates from secure and dismissing inmates based on a function relating to internalized distress. Similarly, using the four BSI scales and the two behavioral adjustment variables, the second discriminant analysis was also able to separate fearful and preoccupied inmates from secure and dismissing inmates based on a function relating to overall psychological distress. Overall psychological distress appears to be more characteristic of fearful and preoccupied inmates than it does of secure and dismissing inmates. Despite the consistency of the exploratory multiple discriminant function analyses with the premises of the study, these results are tentative and possibly invalid, and need to be interpreted carefully because in both analyses the homogeneity of the 
variance-covariance matrices assumption across the four attachment groups was not met. These analyses are only exploratory and will not be discussed further because of the violation of this assumption. 


\section{Discussion}

\section{Review of Predictions}

Based on a review of attachment theory and research and the prison adjustment literature, it was hypothesized that adult inmates who exhibit Secure (S) or Dismissing (D) attachment patterns would adjust better emotionally and behaviorally to a prison environment than either Fearful (F) or Preoccupied (P) inmates. Specifically, it was predicted that $\mathrm{S}$ and $\mathrm{D}$ inmates would have lower levels of depression, anxiety, selfesteem difficulties, anger, and overall psychological distress than $\mathrm{F}$ and $\mathrm{P}$ inmates. Further, it was predicted that the former would have fewer and less severe disciplinary violations during imprisonment than $\mathrm{F}$ and $\mathrm{P}$ inmates. The study was conducted to test these predictions as a means of bridging the gap between studies of infant attachment (which focused largely on reactions to separation from attachment figures) and adult attachment (which has focused more on relationship processes rather than separation reactions). In addition, the results may suggest points of intervention for mental health professionals working both inside of and outside of correctional facilities. Emotional indicators of prison adjustment will be reviewed first.

\section{Emotional Adjustment}

Overall, the results of the study partially support the hypotheses. In examining the Brief Symptom Inventory (BSI) scales of interest, clear differences emerge between the S and D groups and F and P groups. On the Global Severity Index (GSI) scale, which is a general indicator of current psychological distress (Derogatis, 1992; Boulet \& Ross, 997), both $\mathrm{F}$ and $\mathrm{P}$ inmates scores were higher than those of $\mathrm{S}$ and $\mathrm{D}$ inmates suggesting that 
they are exhibiting more overall emotional distress within the prison environment. It is interesting to note that the means for the $P(M=68.88)$ and $F(M=67.03)$ inmates are well above one standard deviation ( $\mathrm{SD}=10$ ) from the mean of 50 on the $\mathrm{BSI}$, suggesting that emotional difficulties are a real area of concern for these men. It would appear that inmates with these patterns' negative self-views and dearth of internal resources exhibit increased psychological distress in adjusting to the prison environment and separation from loved ones. Conversely, it appears that the positive self-views of S and D inmates act as a buffer in the difficult transition to prison.

A similar pattern emerges when examining the Depression (DEP) and Anxiety (ANX) scales of the BSI. On both of these scales F and P inmates have higher scores than $\mathrm{S}$ and $\mathrm{D}$ inmates. Again, $\mathrm{F}$ and $\mathrm{P}$ inmates have mean scores which are greater than one standard deviation from the mean, suggesting that $\mathrm{F}$ and $\mathrm{P}$ inmates have real, clinically elevated concerns in the areas of current, explicit feelings of anxiety and depression.

On the hostility (HOS) scale of the BSI, the F and P inmates have higher scores than $\mathrm{S}$ inmates. $\mathrm{D}$ inmates did differ on this scale than either $\mathrm{P}$ or $\mathrm{F}$ inmates. $\mathrm{P}$ inmates mean score, however, was greater than one standard deviation above the mean suggesting that they have clinically elevated levels of hostility.

Overall, results from the BSI seem to strongly support the notion that inmates exhibiting S and D attachment patterns adjust better to incarceration and separation from family than F and P inmates. Particularly in the areas of Depression, Anxiety, and Global Distress, $\mathrm{F}$ and $\mathrm{P}$ inmates appear to have real emotional difficulties as they enter the 
prison system and leave their family and friends behind. In that both of these patterns have inherently poor views of themselves and depend highly on others for support (Bartholomew, 1990), it is not surprising that a threatening, isolating environment such as a prison would bring out feelings of depression, anxiety, and other symptoms. On the other hand, S and D inmates appear to adjust reasonably well to the same conditions. Both of these patterns share a positive view of the self. In addition, $S$ inmates believe their families and loved ones are still there for them despite the physical separation, and D inmates have learned to not rely on others for support. These inmates can rely on their inherent self-soothing capabilities, while $\mathrm{F}$ and $\mathrm{P}$ inmates have less-developed selfsoothing capabilities (Griffin and Bartholomew, 1994). Only results on the HOS scale did not confirm the predictions in that the $\mathrm{D}$ inmates mean scores did not differ from those of the $\mathrm{P}$ or $\mathrm{F}$ inmates. Perhaps hostility is not as salient a factor as depression or anxiety in that these latter two areas may be more likely to result from being separated from loved ones than a sense of anger. In addition, anger may require a sense of being disrespected by someone and the poor self-views of $\mathrm{F}$ and $\mathrm{P}$ inmates may prohibit such a feeling from occurring or may inhibit their expression of these feelings. If so, it makes sense that these inmates did not have particularly high levels of hostility.

Turning now to the Minnesota Multiphasic Personality Inventory (MMPI-2) Content scales, a slightly different pattern emerged. On the Depression (DEP) scale, F inmates had higher scores than both $\mathrm{S}$ and $\mathrm{D}$ inmates, while the $\mathrm{P}$ inmates had higher scores than only the $\mathrm{S}$ inmates, lending partial support to the hypotheses. It is interesting to note that $P$ inmates actually had slightly elevated DEP scores (mean of 68.44 ) 
compared to $F$ inmates (mean of 68.19), yet post hoc analyses indicated that $F$ inmates had a higher score than the $\mathrm{D}$ group but the $\mathrm{P}$ group did not (see Table 1). Statistical anomalies aside, both $\mathrm{F}$ and $\mathrm{P}$ inmates had $\mathrm{DEP}$ scores almost twenty points above the mean scores. This suggests that these inmates may have clinically elevated levels of depression in comparison to $\mathrm{S}$ and $\mathrm{D}$ inmates.

A similar picture emerges on the MMPI-2 Anxiety (ANX) scale. Again, both S and $\mathrm{D}$ inmates have lower scores than $\mathrm{F}$ inmates, but only $\mathrm{S}$ inmates have lower scores than the $\mathrm{P}$ inmates. A similar statistical anomaly emerges in that the $\mathrm{P}$ group actually has a slightly elevated mean (67.06) compared to the F group (66.74), and yet only the F inmates have higher scores than the D inmates. And similar to their MMPI-2 DEP scores, both $\mathrm{F}$ and $\mathrm{P}$ inmates may have clinically elevated levels of anxiety as their scale scores are more than one standard deviation above the mean. Secure and dismissing inmates' scores were well within normal ranges on the ANX scale.

Overall, it appears that both the $\mathrm{F}$ and $\mathrm{P}$ groups tend to have higher levels of depression and anxiety when compared to the $S$ and D groups. Secure inmates had lower mean scores on the DEP and ANX scales than both F and P inmates, and D inmates had lower scores on these scales than F inmates. In addition, the F and P groups DEP and ANX scores were more than one standard deviation above the mean, suggesting that these inmates may have clinical elevations in depressive and anxious symptomology, while S and $\mathrm{D}$ inmates scores were well within the normal range. It seems again that the polarity of the self-dimension bolsters the former group (positive self-view), and hinders the latter (negative self-view). 
More mixed results emerge from the final two MMPI-2 Content scales. On the Anger (ANG) scale, the only difference detected was between the $S$ and $F$ inmates where $\mathrm{S}$ inmates had fewer difficulties with anger than $\mathrm{F}$ inmates. On the Low Self-Esteem (LSE) scale, both $\mathrm{P}$ and $\mathrm{F}$ inmates had higher scores than $\mathrm{S}$ inmates suggesting they have poorer self-views than secure inmates. Dismissing inmates scores were not different from those of the $\mathrm{F}$ and $\mathrm{P}$ inmates on either of these scales. As discussed earlier, perhaps anger is not such a relevant characteristic of insecure attachment in that both $\mathrm{F}$ and $\mathrm{P}$ inmates have a negative self-view and may tend to channel negativity inward (through depression and anxiety) rather than outwardly (anger reactions). Additionally, P inmates LSE score is one standard deviation above the mean suggesting a possible clinical elevation in low self-esteem. Consistent with previous research (such as Bylsma et al. 1997; Diehl, 1997), the $\mathrm{S}$ and $\mathrm{D}$ groups appear to have generally fewer issues with self-esteem than the $\mathrm{F}$ and P groups, in large part because of each groups' views of the self.

Turning now to the mental status interview, both the depression and anxiety score analyses indicate that $\mathrm{S}$ inmates have lower mean scores than $\mathrm{F}$ and $\mathrm{P}$ inmates. $\mathrm{D}$ inmates did not differ from the $\mathrm{P}$ or $\mathrm{F}$ inmates on these scores. On the anger and self-esteem scores, no statistical differences emerged among the four attachment groups. Though not statistically or practically different, on all four of these scales the mean scores are in a direction with $\mathrm{S}$ and $\mathrm{D}$ inmates exhibiting lower raw scores on depression, anxiety, and anger (and higher levels of self-esteem) than $\mathrm{F}$ and $\mathrm{P}$ inmates (see Table 3). There may be several reasons for the lack of statistical differences among the attachment patterns on the mental status interview. A mental status interview was included in this research as a 
different means of discovering inmates' feelings in regard to self-esteem, depression, anxiety, and anger. On the MMPI-2 and BSI, inmates expressed their feelings more privately and in writing, while inmates were asked to discuss emotional difficulties with a stranger on the mental status interview. In addition, the interviews were conducted (because of prison rules) in the presence of other inmates, so perhaps they were less willing to discuss intimate feelings in an environment where others could hear their concerns. Finally, the interview itself and the scores used in this research have not been subjected to the empirical research that both the MMPI-2 and BSI have and thus are likely to be a less empirically valid measurement of complex psychological constructs such as anxiety, depression, anger, and self-esteem.

Taken together, the twelve emotional adjustment indicators garnered from the MMPI-2, BSI, and mental status interview offer partial support for the study's predictions. Secure inmates had lower scores than $\mathrm{F}$ inmates on ten of the 12 emotional adjustment variables, and lower scores than $\mathrm{P}$ inmates on nine of these 12 variables. Additionally, the mean scores of S inmates did not approach clinically elevated levels on the eight scales of interest from the BSI and the MMPI-2, suggesting they have normal levels of depression, anxiety, anger, and self-esteem. Secure inmates appear to have the internal resources (as a result of their positive self-model) to self-sooth despite being in threatening circumstances (Bartholomew \& Horowitz, 1991). Normally under threatening conditions, $\mathrm{S}$ individuals are expected to turn to their attachment figures for care and support. That is not possible in a prison environment, and hence, the individuals are left to rely on their own self-soothing capabilities. These self-soothing abilities 
include feelings of self-confidence as well as having well-developed social and communication skills as well as the capacity to empathize and to be assertive (Diehl, 1998). Secure inmates also have additional reassurance in their belief that loved ones outside the prison walls will not abandon them despite the separation. Their positive other-model assures them that their attachment figures will remain there for them, despite the prison walls between them (Griffin \& Bartholomew, 1994). Overall, then, inmates with a S pattern of attachment had normal-range levels of depression, anxiety, anger, and self-esteem as they adjusted to incarceration and separation from loved ones.

Inmates with a dismissing style of attachment were not far behind in their emotional adjustment to prison. Consistent with the study's predictions, none of the emotional adjustment scores of $\mathrm{D}$ inmates were statistically different from $\mathrm{S}$ inmates. Dismissing inmates had lower scores than $\mathrm{F}$ inmates on five of the 12 emotional adjustment variables, and lower scores than $P$ inmates on 3 of these variables. Unlike the $\mathrm{P}$ and $\mathrm{F}$ inmates, the mean scores of $\mathrm{D}$ inmates did not approach clinically elevated levels on the eight scales taken from the BSI and MMPI-2, suggesting they have normal levels of depression, anxiety, and self-esteem. Again, the result seems to hinge on the positive self dimension of the $\mathrm{D}$ pattern. These inmates have the inner resources to comfort themselves during threatening circumstances (Mikulincer \& Florian, 1995; Mikulincer et al., 1993). In addition, $D$ individuals have learned not to rely on others for support when in a threatening environment, and would expect to rely on themselves whether or not they were incarcerated. The negative other-model $\mathrm{D}$ individuals exhibit leaves them only themselves to turn to for comfort and support. It seems likely that separation from their 
attachment figures because of imprisonment had little impact on their emotional adjustment to prison. They do not have a sense of security in regard to their attachment relationships (as secure individuals have), which may explain their slightly elevated scores compared to $S$ inmates. Overall, though, it appears that both $S$ and $D$ inmates emotionally adjusted the best to incarceration.

Finally, on all twelve indicators of emotional adjustment, fearful and preoccupied inmates had the highest mean raw scores, indicating less than optimal adjustment as compared to $\mathrm{S}$ and $\mathrm{D}$ inmates (see Tables 1 - 3). On eight of these twelve indicators $\mathrm{F}$ inmates had lower raw scores than P inmates, but many of these differences were small and none were statistically significant. This suggests that $\mathrm{F}$ and $\mathrm{P}$ inmates have statistically equivalent scores on the measure of emotional adjustment. Additionally, on the eight BSI and MMPI-2 scales of interest, P inmates had clinically elevated scores (one standard deviation above the mean) on seven of these scales, and F inmates had clinically elevated scores on six of these scales. This suggests that these two attachment groups may have significant impairments emotionally, displaying difficulty with depression, anxiety, anger, and poor self-esteem. What these two attachment patterns share is a negative self-model. Individuals with these attachment patterns are characterized by a dearth of internal resources, such that they look outside themselves for comfort and support when threatened (Bartholomew, 1990). In a prison environment, attachment figures are not accessible, hence only their weak internal resources can be used for selfsoothing in times of distress. Preoccupied inmates would be in an especially difficult bind in that their sense of self is predicated upon their significant relationships (Griffin \& 
Bartholomew, 1994). This over-reliance on relationships is a result of their positive other-model and negative self-model. Fearful individuals have a negative model of both self and other, and are characterized by a disorganized approach in times of distress in the sense that they can not reliably look to self or other for comfort and support. A threatening environment such as a prison seems to only increase their symptoms of distress. For both $\mathrm{P}$ and $\mathrm{F}$ inmates, the prison environment may have led directly to feelings of depression, anxiety, and anger, and poor self-esteem. The lack of internal resources and inaccessibility of attachment figures led to overall poorer emotional adjustment to the prison environment as compared to $S$ and $D$ inmates.

\section{Behavioral Adiustment}

There was not a statistically significant difference among the attachment patterns in regard to either the number or the severity of disciplinary violations while imprisoned. There are several possible reasons for the lack of statistical support for the behavioral adjustment indicators. First, the means by which inmates are cited for disciplinary violations are often based on factors that are not objective. Prison security personnel's decision to cite or not cite an inmate depends on both personal factors (such as personality style, fatigue, prejudices) and situational factors (prison environment, number of duties that an officer is charged with at a particular time). Therefore, some inmates will be cited for violations that other inmates might not be cited for. Second, and perhaps more relevant to this study, attachment styles may affect emotion-regulation strategies more than they affect behavioral-regulation strategies. Especially with the poor selfconcepts of $\mathrm{F}$ and $\mathrm{P}$ individuals, they may tend to internalize their distress rather than 
behaviorally act out. Attachment research has generally focused on discovering differential affect-regulation approaches and relationship variables (e.g., Hazan \& Shaver, 1987; Pistole, 1995), while the prison adjustment literature has focused on behavioral indicators of adjustment (e.g., McShane \& Williams, 1985; Myers \& Levy, 1978).

Demographic variables such as age and prior prison commitment have generally been the strongest predictors of prison misbehavior, not personality variables (Petersilia \& Honig, 1980; Myers \& Levy, 1978). Attachment patterns have been shown to relate to more thoughts, feelings, and behaviors within the context of a relationship, not to acting out behaviors. A combination of selective and non-objective citing of inmates for violations as well as a variable such as acting out behaviors may help explain the lack of statistical significance among the attachment patterns in behavioral adjustment. Additionally the small effect sizes in the analyses of these variables indicate that attachment patterns contribution is of limited practical significance. Future research needs to control for some of these confounds in determining the predictive utility of attachment patterns in regard to acting out behaviors.

The exploratory multiple discriminant function analyses (MDFA) seemed to indicate that, in fact, emotional factors are more descriptive of attachment patterns than behavioral indicators and that emotional difficulties were more characteristic of $\mathrm{F}$ and $\mathrm{P}$ inmates than S and D inmates. Recall, however, that a critical assumption of the MDFA was violated (homogeneity of variance and covariance matrices). This casts serious doubt on the validity of these analyses and therefore they will not be discussed further.

According to theory, attachment patterns should affect both emotional and 
behavioral realms (Bowlby, 1969, 1973, \& 1980). Methodological considerations, particularly the way inmates are cited for disciplinary violations and how these violations are recorded are likely one culprit for the lack of differences among the attachment patterns. Additionally, $\mathrm{F}$ and $\mathrm{P}$ inmates may internalize their distress rather than acting out in anger or with aggression.

\section{Implications}

\section{Attachment Theory Among Infants and Adults}

One of the main goals of this research was to take a tentative step toward bridging the gap between the seminal research conducted on infant attachment by John Bowlby and Mary Ainsworth and the later adult attachment research led by Hazan, Shaver, Bartholomew, and others. Bowlby $(1969,1973,1980)$ initially examined normative attachment processes in infants separated from their caregivers. In so doing he described three distinct phases that infants appear to undergo after significant separations from attachment figures: first, protest (intense crying, anger), then despair (whimpering, resignation, withdrawal), and finally detachment (renewed interest in surroundings). In addition, he proposed the internal working models infants construct of both self (either positive or negative) and other (either positive or negative) based on the early interactions with attachment figures. Ainsworth (1967) took Bowlby's work a step further and examined qualitative differences in the quality of attachment between infant and caregiver. Based on a series of laboratory experiments involving separation and reunion episodes between infants and caregivers, she proposed three distinct patterns of attachment (Ainsworth et al., 1978). 
Much of the adult attachment work has been predicated on the theory and findings from this initial attachment research. However, little research has examined separation reactions in the adult attachment literature and what has been done has methodological and theoretical limitations. Separation reactions and the desire to return to a safe haven when threatened is a basis of attachment theory, and this research sought to specifically examine these phenomena among adults.

Bowlby (1969) described protest and despair reactions as being normative in the initial stages of separation among infants from attachment figures, and the prison adjustment literature describes a period of transition shock when offenders are initially incarcerated (Toch et al., 1989; Zamble \& Porpino, 1990). This transition shock is evidenced by elevated levels of depression, anxiety, anger, and depressed self-esteem. The parallels are evident between these two bodies of research: placed in an unfamiliar environment (which is perhaps perceived as threatening) and separated from attachment figures to whom one would normally turn to for support and comfort, both infants and incarcerated adults exhibit protest and despair reactions. This effect was clearly evident in this research as well. Being tested within the first few weeks of imprisonment, many subjects reported elevated levels of depression, anxiety, anger, and depressed self-esteem. The protest and despair reactions and the transition shock of initial incarceration were apparent in the measure used in the study. The normative aspects of attachment described by Bowlby appear to be present in this sample of adults.

What is interesting to note is the individual differences in these reactions from the frame of attachment patterns, the same patterns described by Ainsworth et al. (1978) in 
her studies of infant separation. The attachment patterns of this sample clearly mediated their adjustment to being separated from loved ones and their adjustment to incarceration. Much as Ainsworth described differential reactions of the secure, avoidant, and resistant infants, inmates characteristic pattern of attachment helped to explain their reactions as well. As expected, Secure and Dismissing inmates generally emotionally adjusted better to the incarceration situation than both Fearful and Preoccupied inmates, especially in regard to feelings of anxiety and depression.

Further, the self and the other models that Bowlby (1973) proposed infants construct based on their attachment relationships help to explain these differential reactions. Bartholomew and Horowitz (1991) based their theorizing on adult attachment on these self and other dimensions, and as described earlier, these dimensions are the basis for four adult patterns of attachment. This research seems to suggest that the 'self' dimension underlying the attachment patterns is particularly salient in a situation where one does not have access to attachment figures. With a positive self-model, S and D inmates adjusted better to separation and incarceration. With a negative self-model, F and $\mathrm{P}$ inmates had difficulties adjusting to the same conditions. The self-model, characterized by views and expectations of the self as well as internal self-soothing capabilities, seemed paramount in successfully adjusting to imprisonment. These selfsoothing capabilities include the ability to be assertive with as well as to empathize with others. It also includes having well developed social skills and a strong internal locus of control (Diehl, 1998). The other-model, characterized by views and expectations of others (particularly attachment figures) was not as salient in the incarceration situation 
since attachment figures were not accessible. The internal working models proposed by Bowlby and later utilized by Bartholomew in her conception of adult attachment allow a parsimonious and meaningful description of separation reactions among adults.

Bowlby, Ainsworth, and other infant attachment researchers believe attachment behaviors characterize humans from the 'cradle to the grave' (e.g., Bowlby, 1979; Ainsworth, 1989). This research would seem to add at least preliminary evidence that this is indeed the case. Protest and despair reactions were evident in infants as well as in this sample of adults when separated from loved ones. The prison adjustment literature suggests that in the initial stages of imprisonment, missing and being separated from loved ones is the most difficult problem faced during incarceration. Again, it would seem that the safe haven phenomena (being separated from loved ones and placed in an environment where one does have access to loved ones leads to desires and attempts to connect with attachment figures), indeed characterized this sample. When reunion can not be achieved with the safe haven of attachment figures, both infants and adults appear to have negative emotional reactions to such an event.

Individual differences in attachment behavior are also evident in that certain patterns of attachment lead to certain patterns of emotional responding in both infants and adults when separated from loved ones. The adult attachment patterns, based on the internal working models proposed by Bowlby, have an affect on separation reactions. Secure and Dismissing adults appear to rely on their positive self-model upon separation to modulate their emotions, and appear to adjust better than $\mathrm{F}$ and $\mathrm{P}$ adults, whom have negative self-models. The individual differences observed in this research parallel 
Ainsworth's (1978) work in that secure and avoidant infants reacted less emotionally and more positively to separation much as their analogs in this research, the $S$ and $D$ inmates.

Taken together, the results from this study appear to go far in beginning to bridge the gap between the infant and adult attachment literatures. The secure base phenomena, the protest and despair reactions, and the importance of the self and the other in the internal working models of humans seems to characterize both the infant literature and the adults studied here. Attachment does seem to characterize humans from the cradle to at least adulthood, if not the grave. While these findings are suggestive, they are far from conclusive. Future research needs to further clarify and expand the connections between the infant and adult attachment literatures.

\section{Adult Attachment Research}

In regard to furthering adult attachment research, several aspects of the study should be considered. The vast majority of research in this area has been conducted with white, middle to upper class college-age samples. This sample was comprised of older, more ethnically and socioeconomically diverse subjects. Interestingly, the distribution of the attachment patterns in this sample was different from most other research in that the most commonly endorsed pattern was the fearful style. In fact, only $32 \%$ of the sample described themselves as having a secure pattern of attachment while in most studies approximately $50-60 \%$ of the samples described themselves as secure (Carver, 1997; Bartholomew, 1994). The reason for this is unclear, but perhaps the family and relational history of inmates tends to be characterized by more negative events than college samples in that almost $70 \%$ of inmates described themselves as having one of the three insecure 
patterns of attachment.

Additionally, several aspects of the mental status interview addressed inmates' familial histories. Among the findings, only $46 \%$ of the sample said that they were raised by both of their parents. Another $44 \%$ described themselves as not having a positive role model either in or outside of their families while growing up. Approximately $30 \%$ said that they experienced one or more types of either emotional, physical, or sexual abuse. Almost 50\% reported that they witnessed either domestic abuse, substance abuse, or criminal behavior in their immediate family before the age of eighteen. Finally, almost $87 \%$ described having a past or current substance abuse problem, and $100 \%$ of the sample have been convicted of feither a felony or a misdemeanor serious enough to merit a prison sentence of at least six months. Clearly this sample has characteristics quite different than typical college samples, which may help to explain the tilt toward insecure patterns of attachment in this research.

It should also be noted that across methods of measuring adjustment in this study, there was a surprising consistency of results. Dependent measures included an objective personality test (MMPI-2), an assessment of current psychological symptoms (BSI), a one-on-one mental status interview, and a review of disciplinary records. Across some of these methods, $\mathrm{S}$ and $\mathrm{D}$ inmates displayed overall better adjustment than $\mathrm{F}$ and $\mathrm{P}$ inmates. In particular the most empirically researched and valid dependent measures included in the study, the BSI and MMPI-2, clearly indicated that the S and D inmates adjusted much better to imprisonment. The mental status and disciplinary record measures, where statistical differences were less evident, have not been empirically validated. Much of the 
adult attachment research to date has used self-report measures of emotional phenomena exclusively, and this study suggests that attachment processes can be captured by a number of different means. As results in particularly the behavioral realm were not practically nor statistically significant, a more powerful research design may be needed in the future.

Finally, since Bartholomew and Horowitz (1991) first described their four category model of adult attachment, the self and other dimensions they postulated (and brought forward from Bowlby's work) seem to add meaningfully to the literature. This research further bolsters their meaning in that the self-model clearly affected separation reactions in this sample. The other-model, while still relevant in that it is this dimension that one has a sense of felt security that loved ones will be there for them, did not seem to affect adjustment reactions to incarceration as strongly. Rather it was the internal resources which are part and parcel of the self-model which were most influential. This research indicates that the self- and other-models appear to allow useful and meaningful descriptions of attachment related phenomena, particularly in regard to separation reactions.

\section{Prison Adjustment Research and Application}

As described earlier, the prison adjustment literature has historically examined inmates factors which are related to behavioral difficulties while imprisoned (Myers \& Levy, 1978; McShane \& Williams, 1989). Variables such as youth and no prior incarcerations have typically been linked to higher rates of inmate maladjustment. The aim of much of this research was to be able to predict for prison management personnel 
which inmates were most likely to display management problems for security reasons (Adams, 1977). Other research has examined variables which relate to more maladaptive emotional reactions to imprisonment (Schmid \& Jones, 1993; Toch et al., 1986). The aim of this research was to guide mental health professionals working within correctional systems to more accurately assess and more efficiently treat inmate clients. This research appears to add meaningfully to both these bodies of research.

There was no difference among the attachment patterns in the number and severity of disciplinary violations. The lack of statistical significance could be attributed to one of many possible methodological flaws: (1) the possible selective citing of inmates for violations and inaccurate or inconsistent record-keeping, (2) the time frame studied may have been too short, or (3) not all behavioral manifestations of attachment reactions fall under the prison's disciplinary code. Whatever the reason, this study suggests that attachment patterns do not have a robust relationship with behavioral adjustment as measured here. Future research may want to study behavioral adjustment with a more controlled research design. Demographic factors such as age and prior incarcerations continue to have the strongest relationship to behavioral difficulties while imprisoned.

In examining emotional adjustment to the prison environment, however, attachment patterns offer much more to concern mental health professionals within such settings. Both P and F inmates had scores on the BSI and MMPI-2 suggestive of pronounced, clinically elevated difficulties with overall psychological distress, depression, anxiety, self-esteem, and to a lesser extent, anger. Secure and Dismissing inmates did not exhibit nearly as much emotional distress while imprisoned. Therefore, 
assessing for attachment patterns and their concomitant views of self and of other could be a useful tool in predicting inmates who may have need of psychological services while imprisoned. Missing family and friends has been highlighted in other research as being a very salient problem for inmates (Zamble \& Porpino, 1990; Flanagan, 1981), and perhaps supportive individual and group therapies may be used with these inmates to reduce their distress. Short-staffed correctional mental health agencies may only be able to offer supportive therapies, but if the resources are available for long-term treatment, these inmates could benefit from an examination of their negative self-views. Examining their family and relational histories and seeing how their views of themselves have developed would be the first step, and then these lessons need to be applied to the present to see how defensive processes of the past are now adversely affecting their lives. In addition, if prison systems are legitimately interested in reducing inmates' psychological distress, perhaps existing visiting policies need to be re-evaluated. Especially during the transition shock of initial imprisonment, increased access to families via extended visiting hours may (a) reduce some of the inmates emotional distress, and (b) reduce the strain on severely limited prison mental health resources. This study clearly documented some of the transition shock of imprisonment. The protest and despair first described in infants is quite characteristic of F and $\mathrm{P}$ inmates in their elevated levels of anxiety and depression. Attachment processes seem to document and describe this transition shock quite well.

\section{Clinical and Counseling Implications}

While the main thrust of this study was to examine separation reactions among adults as well as to begin to connect the infant and attachment literatures, several clinical 
and counseling implications appear to be relevant from this research. As previously discussed, correctional psychologists should pay heed to familial issues as well as pattems of attachment in conceptualizing inmate issues as this research uncovered a relationship between $\mathrm{F}$ and $\mathrm{P}$ attachment patterns and problems with general psychological distress, depression, and anxiety. Exploring and discussing these issues in either an individual or group format relating to inmates' separation from their families and the feelings these bring up for them may help to relieve their distress.

On a more general level of clinical application, these results may stimulate thinking in the assessment and treatment of those dealing with issues such as permanent or temporary separation from loved ones, grief and loss, and general relationship difficulties. It appears that ones' pattern of attachment to significant others mediates both thoughts and feelings during times of separation, distress, and conditions of duress. By assessing clients' underlying attachment patterns, and their general views and expectations of both the self and of others, one may be able to develop a more individualized, and possibly more effective, treatment plan to explore clients feelings and minimize their distress. Attachment phenomena should be prevalent in couples work as well, in that identifying partners' underlying views of self and other may help clarify issues within the dyad. By assessing partners views of themselves and their significant other, one can grasp what seems to be a complicated relationship dynamic in a more concrete, understandable way. Attachment seems to have much to offer in assessing and treating clients with these types of presenting issues.

Further, this research suggests that the underlying self- and other-models 
associated with each of the four attachment patterns is a general, yet individualized, way in which therapists could conceptualize clients' lives. For example, a client with a Preoccupied attachment pattern has a negative view of self and a positive view of others. These general "types" of individuals display dependency in that their sense of self is constructed through their relationships with the significant people in their lives (Bartholomew, 1990). When left with just themselves, they may feel quite empty, scared, and confused about who they are and what they value. These individuals may become anxious or depressed and would benefit from treatment. In the midst of a consistent relationship, these individuals would likely appear to be satisfied and happy at times, but dependent, insecure, and anxious at other times. Examining these clients' views of themselves, their views of others, and their family and relational history may help both therapist and client alike in understanding some of the instability of their relationships and their self-concepts. Each of the three insecure attachment patterns have places of entry for clinicians, where one could explore issues with clients, and help them understand some of their conflicted, confusing feelings.

While attachment patterns are a useful schema for assessing client issues, they also may offer a blueprint for treatment. If attachment patterns are based on one's attachment history with first parents, and later with other significant persons in a client's life, exploring this history in the counseling relationship would be at least insightful for clients. In that views of self and of other are thought to be constructed by infants to help them understand and predict the often confusing world around them, perhaps some of these constructs are defensive in nature. An individual with a Preoccupied attachment 
pattern may expect inconsistent support, care, and nurturance from others, and hence may defend against further self injury by investing all of their energies in connecting to others, at the expense of their own needs. When these needs were expressed openly earlier in their history, perhaps they were sensitively taken care of at some times, but other times they were rebuffed. These rebuffs may have become so hurtful to the self, so unacceptable to the developing individual, that they are buried in their unconscious. Instead of expressing their needs, they now look to others for their sense of self, their sense of purpose, and their sense of happiness. But these unexpressed needs still exist, as deeply buried as they may have become over time. Working with clients such as these may involve a journey to the past to discover and develop their identities, needs, values, and desires. Defensive processes that were effective at earlier times in their lives no longer work in the present, and need to be abandoned so that the true self can develop. Attachment theory and individual differences in attachment histories and attachment patterns offer the therapist a way of entering and empathetically understanding a client's worldview. They also offer a road map to how client's current concerns are directly and indirectly connected to their past. Support and understanding would be paramount in beginning this journey with clients. Later, sensitively challenging some of the client's views of self and others in the context of a safe relationship with the therapist would be necessary. Attachment theory offers much to the understanding of client feelings, thoughts, and concerns.

While psychoanalytic, object relations, and other therapeutic modalities all stress the importance of ascertaining an understanding of a clients past in treatment, this 
research suggests a way of prioritizing client concerns. In this sample, Secure and Dismissing inmates displayed fewer current depressive and anxious symptoms than other inmates. These inmates have a positive sense of self. Fearful and Preoccupied inmates both have a negative sense of self, and both displayed anxious and depressive symptoms. Attachment theory suggests that $S$ individuals are the healthiest in that they have positive views of both themselves and others (Ainsworth et al., 1978; Bartholomew, 1990). Consequently, F individuals would be the least healthy in that they have negative views of both self and other. For Fearful individuals, it would appear to be most beneficial in focusing on the negative view of self first, in that a positive sense of self builds a sense of resiliency in the face of troubling circumstances. Later in therapy, working on their views of others, and helping them understanding how their past relationship history has resulted in a sense of distrust of and insecurity in others, would be indicated. But the exploration and healing of the self seems to be the priority.

Dismissing individuals, while still insecure in their attachments, seem to do reasonably well when faced with troubles in their lives. When working with these individuals in treatment, the treatment begins with an exploration of their views of others. But one must be sensitive to changes in their views of themselves as well in that it is thought their positive sense of self is constructed defensively. Preoccupied clients have a negative view of themselves and a positive expectations of others. The work begins here on the sense of self, but again, the positive views of others is also defensively constructed and must continually be addressed.

Overall, this research suggests that the best way to reduce clients' distress may be 
to examine their self-concept first. By exploring the past, and slowly re-constructing a more realistic view of themselves in the context of their current environment, therapists may guide clients toward leading more satisfying lives. Later, the same process of exploration and re-construction of views and expectations of others would be indicated. This research suggests that relieving distress hinges more on addressing views of self rather than views of other. While both are ultimately crucial in assessment and treatment, addressing self issues first may help forge a sense of resiliency within clients as they begin to explore their views and expectations of other important people in their lives. It is important to note that these are tentative treatment suggestions, and careful outcome research would be necessary to establish their validity. However, the research presented here suggests that a positive self-model seems to override either positive or negative other-models in determining who will exhibit symptoms of anxiety or depression when separated from loved ones in a prison environment. The resiliency of a positive selfmodel clearly had an affect in the results of this study.

\section{Limitations of the Study}

There are several limitations that must be taken into account in evaluating this research. Though the subject pool was purposefully chosen to address past limitations of attachment research (which have typically used white, middle class college-age students), several aspects of the sample may limit the study's generalizability. The sample was all male and comprised of individuals convicted of a variety of felonies and misdemeanors. The cost of using an older and more culturally diverse sample is the possibility of limited external validity. Whether these results apply to females, or to individuals without a 
criminal history, depends on replicative studies in the future.

Secondly, the use of a self-report measure of attachment may be problematic as well. Attachment patterns are thought to be a summary of a person's family and relational history which is the basis for the development of cognitive models of both themselves and other people (Bowlby, 1973; Bartholomew, 1990). Whether or not individuals have conscious access to these models, and have the ability to describe these historically developed models is a question that continues to be debated within the attachment field. Much of the adult attachment literature has used self-report measures to identify patterns of attachment. The field then, appears to accept the assumption that individuals do have conscious access to their internal working models (Bartholomew, 1994). This research is predicated on the same assumption. Additionally, infant attachment researchers assess attachment patterns through observational and experimental methods. The divergence in assessment methods between the infant and adult attachment fields may limit attempts to integrate these separate research bodies, as this study intended to do.

Methodologically, the study has several limitations as well. While different outcome methods were purposefully chosen to cross-validate the results, both the mental status interview and behavioral measures failed to reveal any statistically significant differences among the attachment patterns. Perhaps these methods lack the necessary power and control to detect such differences. How inmates were cited for disciplinary violations and the ways in which inmates' records were maintained were beyond the observation and control of the experimenter. Additionally, because the restrictive 
conditions in which researchers were asked to assess inmates, one-on-one mental status interviews were conducted in the same room within several feet of other test subjects. This severely limited confidentiality, and hence, likely limited the openness of some subjects. Future research should attempt to control for such eventualities, as each testing environment comes with its own specific challenges.

\section{Summary and Future Directions}

This study was in large part designed to integrate the developmentally-oriented infant attachment field with the more social psychological adult attachment field. In many ways, it was successful. The protest and despair reactions described by Bowlby were apparent in this sample. The safe haven function (to seek out significant others when distressed) of the attachment system appeared to be activated in this sample, and certain inmates reacted with elevated levels of depressive and anxious symptomology when they could not reach attachment figures. The internal working models proposed by Bowlby (1973) and the influence of the attachment patterns described by Ainsworth et al. (1978) were also highly influential in these results: Individual differences in adjustment reactions could be meaningfully explained by the four attachment patterns and their specific models of self and other. In addition, the differences between the attachment patterns are consistent with the study's hypotheses and predictions. Perhaps most importantly, Bowlby and Ainsworth based their theory and research upon observing infants' reactions to physical separation from their attachment figures. Adult attachment researchers have largely ignored studying such situations, yet these situations are the basis for the field. This study specifically examined such separations, in addition to addressing 
other methodological weaknesses in past adult attachment research (such as using a more diverse sample and including multiple methods of dependent measures). Future research needs to continue to narrow the gap between these two burgeoning fields. Designing studies based on the original tenets of attachment theory in studying adults seem paramount. While this study examined separation dynamics, future research could study reunion episodes between attachment figures, for example. Finally, continuing attention to measurement issues is also necessary. Adult attachment researchers continue to assess attachment patterns in a variety of ways, and there is a need to cross-validate results across assessment modalities.

Attachment theory and research has provided a useful and intriguing means of understanding human nature, relationships, and personality dynamics in its first forty years of existence. This study was a preliminary step toward integrating two separate, but growing, areas of the field. The gap has been narrowed, and it is the impetus of current researchers to continue this type of challenging but necessary work. 


\section{Appendix A}

The following paragraphs describe ways people act or feel in emotionally close relationships. By

emotionally close, we mean both romantic and non-romantic relationships that you would characterize as close (i.e., caring relationships with others you trust and like or love very much). For example, you might have emotionally close relationships with your parents, romantic partners, etc. Please read each of the four descriptions below (A, B, C, and D) and indicate how much each describes the way you are or probably would be in emotionally close relationships.

\section{Circle One Number for each Description}

A. It is relatively easy for me to become emotionally close to others. I am comfortable depending on others and having others depend on me. I don't worry about being alone or having others not accept me.

$\begin{array}{ccc}\text { not at all } & \text { somewhat } & \text { very much } \\ \text { like me } & \text { like me } & \text { like me }\end{array}$

B. I want to be completely emotionally intimate with others, but I often find that others are reluctant to get as close as I would like. I am uncomfortable being without close relationships, but I sometimes worry that others don't value me as much as I value them.

$\begin{array}{ccc}\text { not at all } & \text { somewhat } & \text { very much } \\ \text { like me } & \text { like me } & \text { like me }\end{array}$

C. I am comfortable without close emotional relationships. It is very important to me to feel independent and self-sufficient, and I prefer not to depend on others or have others depend on me.

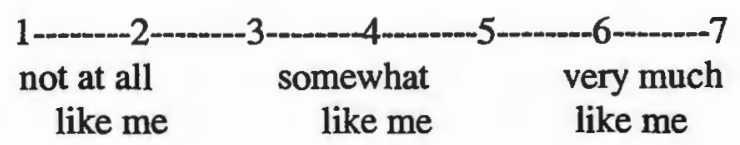

D. I am somewhat uncomfortable getting close to others. I want emotionally close relationships, but I find it difficult to trust others completely, or to depend on them. I sometimes worry that I will be hurt if I allow myself to become to close to others.

$\begin{array}{lll}\text { not at all } & \text { somewhat } & \text { very much } \\ \text { like me } & \text { like me } & \text { like me }\end{array}$

Now go back and put a check on the line preceding the one description that you feel describes you best. 


\section{Appendix B}

\section{Adult Correctional Institute \\ MentaV/Affective Status and History Checklist}

Name:

ID\#:

Age:

DOB: DOE: Language: English(1)__Spanish(2)__Bilingual(3)__Other(4)

Marital Status: Single(1)_ Married(2)__ Divorced(3)__Separated(4)__Widowed(5)__ Sig. Other(6)

Ethnicity: White(1)__ Black(2)__Hispanic(3)_ Asian(4)__ Native American(5)_CV(6)_Other(7)_

Place of Birth: USA(1)__ Puerto Rico(2)__ Dom. Rep(3)__ Guat(4)__Mexico(5)__Other(6)

-COURT/INSTITUTIONAL RECORD:

Sentenced for: \{code: CAPerson(1), CAProperty(2), Drug(3), Sex(4),

Other(5)\}

Length of Sentence: Sentencing Date: Previously incarcerated?: Y N Total \#:

\section{DRUG HISTORY:}

Type:

Alcohol(1)

Cocaine(2)

Marijuana(3) Heroin(4)

Other(5

Age of Onset:

Frequency/Amount:

(Days/week; times/day)

TX History:

Poly-sub. use(6) Sub. use denied(7) Sub. involved in crime? Y N Interest in sub. treatment? Y $\mathrm{N}$

Do you feel that your substance use has interfered with your work, family relationships, education? Y N

\section{EDUCATION:}

Highest Grade Completed? GED? Y N Plan to pursue GED? Y N Special Education: Y $\mathrm{N}$

Learning Disability: $\mathrm{Y} N$

Behavioral Problems in school? Y N (expelled, detentions, conduct problems, etc.) 
For? Beh. probs.(1)_ Affect(2)__ Family(3)__ Court ordered(4)_ Other(5)

Interested in seeing ACI counselor? Y N For? Affective disorder(1)__ Substance Abuse(2)__Other(3)

Seen ACI counselor before? Y N Pink slip filed? Y N Recommended? Y N Call Health Services? Y N

MEDICAL CONDITIONS:

1) 2) 3)

Current Medications: \{code: (1)anti-depressants, (2)anxiolytics, (3)lithium, (4)anti-psychotic, (5)non-psychiatric, (6)multiple medications, (7)other, (8)none

Previous head injury? Y N Hospitalized? Y N

Headaches? Y N

Loss of consciousness? Y N Memory/Concentrations problems? Y N Seizures? Y N -...-... FAMILY HISTORY:

Raised by: single parent(1) both parents(2) other adult(3) foster care(4)__ step family(5)

Before the age of 18, were your parents: Divorced/Separated? Y N Widowed? Y N Which parent?

(2)father

\{code: (1)mother,

Did you have a positive adult role model growing up? Y N Who? \{code:

(1)mother, (2) father, (3)fem. relative, (4)male relative, (5)fem. non-relative, (6)male non-relative, (7)nobody, (8) both parents ]

Parental/guardian behaviors witnessed in home: (check those that apply) domestic violence(1) substance abuse(2) criminal history(3) multiple(4) none(5)

Abuse History: physical(1) sexual(2) emotional(3) multiple(4) none(5)

Do you have any children? Y N How many? Were you living with them? $\mathrm{Y} N$

On average, how many visitors do you receive a week?

From 1 (very little) to 10 (very much), how much do you miss your family? Your friends?

From 1 (very insecure) to 10 ( very secure), how secure are you in the belief that your family will be there for you after your sentence? How secure are you that your friends will be there for you?

What is the single most difficult problem you face being in prison?

(code as " 1 " if there is mention of anything related to missing family or friends; " 2 " for anything else) Current social support network: Strong(1) Average(2)__Poor(3) 


\section{CURRENT MENTAL/AFFECTIVE STATUS:}

Depression Screening:

Feelings of sadness? $\mathrm{Y} N$ Hopelessness? $\mathrm{Y}$ N Worthlessness? $\mathrm{Y} N$ Loss of appetite? $\mathrm{Y} N$

Sleeping difficulties? Y N Energy level: same(1)__ more tired(2)__ less tired(3)__ Loneliness? Y $\mathbf{N}$

Suicidality? Y N Plan? Y N Self-Esteem(1-10):

Total \# "yes" responses to depressive symptoms (don't include "Plan" or "Self-Esteem"): out of 8

Anxiety Screening:

Feelings of nervousness? Y N Tenseness? Y N Irritable? Y N Fearful? Y N Panic attacks? Y N

Total \# "yes" responses to anxiety symptoms: out of 5

PTSD:

Have you experienced yourself or witnessed a traumatic or life-threatening event (e.g., a violent assault, car accident, war injuries)? $\mathrm{Y}$ N

Nightmares? Y N Flashbacks? Y N Persistent memories? Y N

Total \# "yes" responses to PTSD symptoms (don't include event question): out of 3

Ang/Host:

Current Anger (1-10):___ Currently, are you having difficulty controlling your anger? Y N

Thought Disorder:

Delusions Y N Hallucinations Y N Disorganized speech Y N

Total \# "yes" responses to psychological symptoms: out of 3

Strengths:

(1)

(2)

(3)

OBSERVATIONS:

General Appearance:

(check all that apply)

Test-taking approach

forthcoming(1)

guarded(2)

suspicious(3)

motivated(4)
Affective

appropriate(1)

flat(2)

labile(3)
Cognitive

organized(1)

disorganized(2)

alert(3)
Behavior

cooperative(1)

uncooperative(2)

disruptive(3) 


\section{Appendix C}

\section{MMPI-2 Research-Classes of Offenses}

\section{Level 1 Offense (Escape)}

1. (1d) Escape from the institution. Leaving a correctional facility without authorization, leaving escorted custody without permission, exceeding limits of community release without permission, or failing to properly return from a furlough or work detail.

\section{Level 2 Offenses (Assaultive Behaviors)}

1. (1b) Committing an assault and/or battery.

2. (1c) Committing or participating in a/or inciting to riot in any part of the institution or on any work assignment.

3. (1e) Hostage taking of any person.

4. (1h) Sexual misconduct and activity (assaultive only).

5. (2a) Fighting.

\section{Level 3 Offenses (Threatening Behaviors)}

1. (1f) Extortion of any person, staff, or inmate.

2. (1g) Making or having possession of any type of dangerous weapon or facsimile.

3. (2e) Threats. Making verbal/written statements, or engaging in physical conduct intended to cause fear in another person.

\section{Level 4 Offenses (Defiance of Institutional Structure)}

1. (1j) Tampering with a security and/or locking device and/or possession of an instrument for this purpose.

2. (2d) Disregard, neglect or refusal to work, disobeying a lawful order or written rule.

3. (2f) Hiding. Being present and out of sight in an area without authorization.

4. (3a) Failure to report to any required destination without authorization, permission or valid reason, loitering or being in an area longer than necessary to accomplish an authorized purpose. 
5. (3b) Swearing, cursing or use of any vulgar, abusive, insolent or any other improper language toward staff or person visiting the institution or indecency in language or gesture.

6. (3c) Fraudulent request of any type i.e., check request, commissary orders, etc., to circumvent established rules, regulations and procedures for same.

7. (3d) Giving false information to an Officer or employee of the institution.

8. (4c) Refusal to comply with count procedures.

9. (4d) Failure to display inmate identification badge.

\section{Level 5 Offenses (Volitional Infractions)}

1. (1a) Being intoxicated (by homemade or purchased intoxicants) or under the influence of alcohol or drugs, not prescribed by an institutional medical or psychiatric physician, or possession of same including failure or refusal to submit to required examination for urinalysis and/or Breathalyzer and any other test deemed acceptable by authorized officials.

2. (1h) Sexual misconduct and activity (not assaultive).

3. (1k) Possession of controlled medication without prescription and authorization from an institutional medical official.

4. (11) Possession of unauthorized currency over $\$ 5.00$.

5. (1m) Passing or receiving illegal or unauthorized contraband from another inmate, visitor and/or employee.

6. (2b) Stealing and/or unauthorized possession of State property or any property over $\$ 100$ value.

7. (2c) Willfully disfiguring, damaging or destroying any part of the institution or any materials, tools or machine, over $\$ 100$ value.

8. (2g) Tattooing/self-mutilation to oneself or other, to include possession of tattooing equipment.

9. (2h) Gambling of any type.

10. (2i) Wearing or displaying gang colors, identification, or paraphernalia, or recruiting 
for a gang.

11. (3e) Making credit contracts of any form.

12. (3f) Possession of unauthorized currency of $\$ 5.00$ or under.

13. (3g) Passing or receiving legal or permitted contraband from another inmate, visitor and/or employee regardless of the place of occurrence.

14. (4a) Forging or altering an institutional pass.

15. (4b) Making unauthorized phone calls. 


\section{Table 1}

Results for One-Way ANOVAs (mean, probability, F, R-Squared, post hoc tests) for MMPI-2 Scales*

Independent Variable: Attachment Pattern (Secure, Dismissing, Preoccupied, Fearful)

Dependent Variables: Mean scale scores for MMPI-2 Content Scales Low SelfEsteem(LSE), Anger (ANG), Anxiety (ANX), Depression (DEP)**

\section{Mean MMPI-II Scale Scores}

Scale Secure(S) Preocc(P) Dismissing(D)

\begin{tabular}{llll}
\hline LSE & 49.98 & 62.00 & 54.55
\end{tabular}

$\begin{array}{llll}\text { ANX } & 55.45 & 67.06 & 59.00\end{array}$

$\begin{array}{llll}\text { DEP } & 56.85 & 68.44 & 61.08\end{array}$

ANG 51.79

57.63

55.70

Notes:

*ANOVAs calculated using alpha $P<.05$ and have degrees of freedom of $F(3,163)$

**The mean of the MMPI-II contents scales is fifty and the standard deviation is ten

\begin{tabular}{|c|c|c|c|c|}
\hline Fearful (F) & F-Ratio & Sig Level & R-Sg & Tukey Test \\
\hline 58.24 & 6.59 & $<.05$ & .11 & $\mathbf{S}<\mathbf{P}, \mathbf{F}$ \\
\hline 66.74 & 10.65 & $<.05$ & .16 & $S<P, F ; D<F$ \\
\hline 68.19 & 12.21 & $<.05$ & .18 & $S<P, F ; D<F$ \\
\hline 61.48 & 5.85 & $<.05$ & .10 & $S<F$ \\
\hline
\end{tabular}
$S<F$ 
Table 2

Results for One-Way ANOVAs (mean, probability, F, R-Squared, post hoc tests) for BSI Scales*

Independent Variable: Attachment Pattern (Secure, Dismissing, Preoccupied, Fearful)

Dependent Variables: Mean scale scores for BSI Scales Hostility (HOS), Anxiety (ANX), Depression (DEP), Global Severity Index (GSI)**

\begin{tabular}{|c|c|c|c|c|c|c|c|c|}
\hline \multirow[b]{2}{*}{ Scale } & \multicolumn{4}{|c|}{ Mean BSI Scale Scores } & \multirow[b]{2}{*}{ F-Ratio } & \multirow[b]{2}{*}{ Sig Level } & \multirow[b]{2}{*}{ R-Sq } & \multirow[b]{2}{*}{ Tukey Test } \\
\hline & $\underline{\text { Secure(S) }}$ & $\operatorname{Preocc}(\mathbf{P})$ & Dismissing $(\mathbf{D})$ & Fearful(F) & & & & \\
\hline$\overline{\text { HOS }}$ & 49.98 & 60.94 & 54.93 & 57.02 & 6.11 & $<.05$ & .10 & $\mathbf{S}<\mathbf{P}, \mathbf{F}$ \\
\hline ANX & 51.28 & 61.94 & 52.78 & 61.34 & 9.16 & $<.05$ & .14 & $\mathbf{S}<\mathbf{P}, \mathbf{F} ; \mathbf{D}<\mathbf{P}, \mathbf{F}$ \\
\hline DEP & $\mathbf{5 8 . 4 2}$ & 68.69 & $\mathbf{5 9 . 8 0}$ & 66.21 & 7.34 & $<.05$ & .12 & $\mathrm{~S}<\mathrm{P}, \mathrm{F} ; \mathrm{D}<\mathbf{P}, \mathbf{F}$ \\
\hline GSI & 55.66 & 68.88 & 59.70 & 67.03 & 11.77 & $<.05$ & .18 & $\mathbf{S}<\mathbf{P}, \mathbf{F} ; \mathbf{D}<\mathbf{P}, \mathbf{F}$ \\
\hline
\end{tabular}

Notes:

*ANOVAs calculated using alpha $P<.05$ and have degrees of freedom of $F(3,163)$

**The mean of the BSI scales is fifty and the standard deviation is ten 


\section{Table 3}

Results for One-Way ANOVAs (mean, probability, F, R-Squared, post hoc tests) for Mental Status Interview and Disciplinary Violations***

Independent Variable: Attachment Pattern (Secure, Dismissing, Preoccupied, Fearful)

Dependent Variables: Means for Depression Score from Mental Status (DEP), Anxiety Score from Mental Status (ANX), Anger Score from Mental Status (ANG), Self-Esteem Score (S-EST), Number of Disciplinary Violations (\#Disc), Severity of Disciplinary Violations (SevDisc)

\begin{tabular}{|c|c|c|c|c|c|c|c|c|}
\hline \multicolumn{9}{|c|}{ Mean Scores of Mental Status and Disciplinary Variables } \\
\hline Scale & Secure(S) & Preocc(P) & Dismissing(D) & Fearful(F) & F-Ratio & Sig Level & $\underline{\mathbf{R}-\mathbf{S} \mathbf{q}}$ & Tukey Test \\
\hline DEP & 1.87 & 3.19 & 2.23 & 3.07 & 5.35 & $<.05$ & .09 & $\mathbf{S}<\mathbf{P}, \mathbf{F}$ \\
\hline ANX & .83 & 1.94 & 1.10 & 1.66 & 4.88 & $<.05$ & .08 & $\mathbf{S}<\mathbf{P}, \mathbf{F}$ \\
\hline ANG & 3.43 & 4.44 & 3.63 & 4.71 & 2.15 & 096 & .04 & **Non-Signif \\
\hline S-EST & 7.70 & 6.06 & 7.43 & 6.65 & 3.24 & $<.05$ & .07 & *None detected \\
\hline \#DISC & 3.13 & 5.56 & 2.73 & 3.98 & 1.27 & 286 & .02 & **Non-Signif \\
\hline SevDisc & 6.13 & 11.63 & 5.48 & 8.02 & 1.55 & .203 & .03 & **Non-Signif \\
\hline
\end{tabular}

* The Tukey test did not detect differences in post hoc comparisons of the attachment groups on the Self-Esteem score

** The omnibus F-test was not significant so post hoc comparisons were not computed

***ANOVAs calculated using alpha $P<.05$ and have degrees of freedom of $F(3,163)$ 
Table 4

Multiple Discriminant Function Analysis*

(Correlation Coefficients and Standardized Coefficients for the Single

Significant Function Extracted in the Analysis)

Predictors: MMPI-2 Content Scales DEP, ANX, LSE, and ANG, and the mean number and severity ranking of recorded disciplinary violations while imprisoned

Grouping Variable: Attachment Pattern (Secure, Preoccupied, Dismissing, Fearful)

\begin{tabular}{lcl}
\hline Variable & $\begin{array}{l}\text { Correlation Coefficient } \\
\text { with Discriminant Function }\end{array}$ & $\begin{array}{l}\text { Standardized } \\
\text { Coefficients** }\end{array}$ \\
$\begin{array}{l}\frac{.95}{\text { MMPI-2 DEP }} \\
\text { MMPI-2 ANX }\end{array}$ & .89 & .39 \\
MMPI-2 LSE & .66 & -.23 \\
MMPI-2 ANG & .64 & .16 \\
\# Disc Violations & .22 & -.03 \\
Severity of Violations & .25 & .09 \\
\hline
\end{tabular}

* The separation and interpretation of the discriminant function is based on relative contribution of both the correlation coefficients and the standardized coefficients

** Pooled within-groups correlations between discriminating variables and standardized canonical discriminant functions 
Table 5

Group Centroids for Each Attachment Pattern

(Unstandardized canonical discriminant functions evaluated at group means)

\begin{abstract}
Attachment Pattern
\end{abstract}
Mean Value on Function*

$-.58$

Secure

.47

Preoccupied

$-.21$

Dismissing

.54

Eearful 


\section{Table 6}

Multiple Discriminant Function Analysis*

(Correlation Coefficients and Standardized Coefficients for the Single

Significant Function Extracted in the Analysis)

Predictors: BSI Scales GSI, ANX, DEP and HOS, and the mean number and severity ranking of recorded disciplinary violations while imprisoned

Grouping Variable: Attachment Pattern (Secure, Preoccupied, Dismissing, Fearful)

\begin{tabular}{lcl}
\hline Variable & $\begin{array}{l}\text { Correlation Coefficient } \\
\text { with Discriminant Function }\end{array}$ & $\begin{array}{l}\text { Standardized } \\
\text { Coefficients** }\end{array}$ \\
\cline { 2 - 3 } BSI GSI & .94 & .72 \\
BSI ANX & .83 & .28 \\
BSI DEP & .75 & .04 \\
BSI HOS & .63 & -.06 \\
\# Disc Violations & .29 & -.31 \\
Severity of Violations & .26 & .61 \\
\hline
\end{tabular}

* The separation and interpretation of the discriminant function is based on relative contribution of both the correlation coefficients and the standardized coefficients

** Pooled within-groups correlations between discriminating variables and standardized canonical discriminant functions 
Table 7

Group Centroids for Each Attachment Pattern

(unstandardized canonical discriminant function evaluated at the group means)

Attachment Pattern

Secure

Preoccupied

Dismissing

Fearful

\section{Mean Value on Function}

$-.53$

.71

$-.28$

.48 


\section{Bibliography}

Adams, T.C. (1977). Characteristics of state prisoners who demonstrate severe

Problems. Journal of Clinical Psychology, 33(4), 1100-1103.

Ainsworth, M.D.S. (1967). Infancy in Uganda: Infant care and the growth of attachment. Baltimore: John Hopkins University Press.

Ainsworth, M.D.S., Blehar, M.C., Waters, E., \& Wall, S. (1978). Patterns of attachment: A psychological study of the Strange Situation. New Jersey: Erlbaum.

Ainsworth, M.D.S. (1985). Attachments across the life-span. Bulletin of the New York Academy of Science, $61,792-812$.

Ainsworth, M.D.S. (1989). Attachments beyond infancy. American Psychologist, 44, 709-716.

Baldwin, M.W. (1995). Relational schemas and cognition in close relationships. Journal of Social and Personal Relationships, 12(4), 547-552.

Baldwin, M.W., Fehr, B., Keedian, E., Seidel, M., \& Thomson, D.W. (1993). An exploration of the relational schemata underlying attachment styles: Self-report and lexical decision approaches. Personality and Social Psychology Bulletin, 19(6), 746-754.

Bartholomew, K. (1990). Avoidance of intimacy: An attachment perspective. Journal of Social and Personal Relationships, 147-178.

Bartholomew, K., \& Horowitz, L.M. (1991). Attachment styles among young adults: A test of a four-category model. Journal of Personality and Social Psychology, 61, 226-244. 
Bartholomew, K. (1994). Assessment of individual differences in adult attachment. Psychological Inquiry, 5(1), 23-27.

Bartholomew, K. \& Thompson, J. (1995). The application of attachment theory counseling psychology. The Counseling Psychologist, 23(3), 484-490.

Ben-Porath, Y.S., Butcher, J.N., \& Graham, J.R. (1991). Contribution of the MMPI-2 Content Scales to the differential diagnosis of schizophrenia and major depression. Psychological Assessment: A Journal of Consulting and Clinical Psychology, 3(4), 634-640.

Ben-Porath, Y.S., McCully, E., \& Almagor, M. (1993). Incremental validity of the MMPI-2 Content Scales in the assessment of personality and psychopathology by self-report. Journal of Personality Assessment, 61(3), 557-575..

Benoit, D., \& Parker, K.C.H. (1994). Stability and transmission of attachment across three generations. Child Development, 65, 1444-1456.

Berman, W.H. (1988a). The relationship of ex-spouse attachment to adjustment following divorce. Journal of Family Psychology, 1(3), 312-328.

Berman, W.H. (1988b). The role of attachment in the post-divorce experience. Journal of Personality and Social Psychology, 54(3), 496-503.

Berman, W.H., \& Sperling, M.B. (1991). Parental attachment and emotional distress in the transition to college. Journal of Youth and Adolescence, 20(4), 427-440.

Berman, W.H., Marcus, L., \& Berman, E.R. (1994). Attachment in marital relationships. In M.B. Sperling and W.H. Berman (Eds.), Attachment in Adults: Clinical and Developmental Perspectives, (pp. 204-231). New York: The Guilford Press. 
Bonta, J. \& Gendreau, P. (1990). Re-examining the cruel and unusual punishment of prison life. Law and Human Behavior, 14(4), 347-372.

Boone, D.E. (1994). Validity of the MMPI-2 depression content scale with psychiatric patients. Psychological Reports, 74, 550-556.

Borgman, R. (1986). "Don't come home again": Parental banishment of delinquent youths. Child Welfare, 64, 295-304.

Boulet, J. \& Boss, M.W. (1991). Reliability and validity of the Brief Symptom Inventory. Psychological Assessment: A Journal of Consulting and Clinical Psychology, 3(3), 433-437.

Bowlby, J. (1958). The nature of the child's tie to his mother. International Journal of Psychoanalysis, 39, 350-373.

Bowlby, J. (1969). Attachment and Loss: Volume 1; Attachment. New York: Basic Books.

Bowlby, J. (1973). Attachment and Loss: Volume 2; Separation, Anxiety and Anger. New York: Basic Books.

Bowlby, J. (1979). The Making and Breaking of Affectional Bonds. London:

Tavistock.Bowlby, J. (1980). Attachment and Loss: Volume 3; Sadness and Depression. New York: Basic Books.

Bowlby, J. (1982). Attachment and loss: Retrospect and prospect. American Journal of Orthopsychiatry, 52, 664-678.

Bowlby, J. (1988). A secure base: Parent-child attachment and healthy human development. New York: Basic Books. 
Bradford, E., \& Lyddon, W.J. (1994). Assessing adolescent and adult attachment: An update. Journal of Counseling and Development, 73, 215-219.

Brems, C. \& Lloyd, P. (1995). Validation of the MMPI-2 low self-esteem content scale. Journal of Personality Assessment, 65(3), 550-556.

Brennan, K.A., Shaver, P.D., \& Tobey, A.E. (1991). Attachment styles, gender, and parental problem drinking. Journal of Social and Personal Relationships, 8, 451466.

Brennan, K.A. \& Shaver, P.D. (1995). Dimensions of adult attachment, affect regulation, and romantic relationship functioning. Personality and Social Psychology Bulletin, 71(3), 767-783.

Bretherton, I., Ridgeway, D., \& Cassidy, J. (1990). Assessing internal working models of the attachment relationship: An attachment story completion task for 3 year olds. In M.T. Greenberg, D. Cicchetti, \& E.M. Cummings (Eds.), Attachment in the preschool years: Theory, research, and intervention, (pp. 273-308). Chicago: University of Chicago Press.

Broday, S.F. \& Mason, J.L. (1991). Internal consistency of the Brief Symptom Inventory for counseling center clients. Psychological Reports, 68, 94.

Brown, B. \& Spevacek, J. (1971). Disciplinary offenses and offenders at two differing correctional facilities. Correctional Psychiatry and Journal of Social Therapy, 17, 48-56. 
Butcher, J.N., Dahlstrom, W.G., Graham, J.R., Tellegen, A., \& Kaemmer, B. (1989). Minnesota Multiphasic Personality Inventory (MMPI-2): Manual for administration and scoring. Minneapolis, MN: University of Minnesota Press.

Butcher, J.N., Graham, J.R., Williams, C.L., \& Ben-Porath, Y.S. (1990). Development and use of the MMPI-2 Content Scales. Minneapolis, MN: University of Minnesota Press.

Bylsma, W., Cozzarelli, C., \& Sumer, N. (1997). Relation between adult attachment styles and global self-esteem. Basic and Applied Social Psychology, 19(1), 1-16. Cafferty, T.P., Davis, K.E., Medway, F.J., O'Hearn, R.C., \& Chappell, K.D. (1994). Reunion dynamics among couples separated during Operation Desert Storm: An attachment theory analysis. In K. Bartholomew \& D. Perlman (Eds.), Advances in Personal Relationships (Vol. 5, pp. 309-330). London: Jessica Kingsley.

Carlson, B. \& Cervara, N.J. (1991). Incarceration, coping, and support. Social Work, 36(4), 279-285.

Carver, C.S. (1997). Adult attachment and personality: Converging evidence and a new measure. Personality and Social Psychology Bulletin, 23(9), 865-883.

Chisholm, S.M., Crowther, J.H., \& Ben-Porath, Y.S. (1997). Selected MMPI-2 scales' ability to predict premature termination and outcome and psychotherapy. Journal of Personality Assessment, 69(1), 127-144.

Clark, M.E. (1994). Interpretive limitations of the MMPI-2 anger and cynicism content scales. Journal of Personality Assessment, 63(1), 89-96. 
Clayton, P.J. (1990). Bereavement and depression. Journal of Clinical Psychiatry, 51(7), 34-38.

Collins, N.L. \& Read, S.J. (1990). Adult attachment, working models, and relationship quality in dating couples. Journal of Personality and Social Psychology, 58(4), 644-663.

Conoley, J.C. \& Kramer, J.J. (1989). The tenth mental measurements yearbook. Lincoln, NE: University of Nebraska Press.

Croog, S.H., Levine, S., Testa, M.A., Brown, B., Bulpitt, C.J., Jenkins, C.D., Klerman, G.L., \& Williams, G.H. (1986). The effects of antihypertensive therapy on quality of life. New England Journal of Medicine, 314(26), 1657-1664.

Davila, J., Hammen, C., Burge, D., Daley, S.E., \& Paley, B. (1996). Cognitiveinterpersonal correlates of adult interpersonal problem-solving strategies. Cognitive Therapy and Research, 20(5), 465-480.

Derogatis, L.R. (1992). Brief Symptom Inventory (BSD): Administration, scoring, and procedure manual, Third edition. Minneapolis, MN: National Computer Systems.

Diehl, S.K. (1998). An exploratory study of attachment styles and their relationship to emotional intelligence in a young adult population. Unpublished manuscript, University of Rhode Island, Kingston.

Elicker, J., Egeland, M., \& Sroufe, L.A. (1992). Predicting peer competence and peer relationships from early parent-child relationships. In R. Parke \& G. Ladd (Eds.), Family-peer relations: Modes of linkage (pp. 77-106). Hillsdale, NJ: Erlbaum. 
Endler, N.S., Parker, J.D.A., \& Butcher, J.N. (1993). A factor analytic study of coping styles and the MMPI-2 Content scales. Journal of Clinical Psychology, 49(4), 523-527.

Erickson, M., Sroufe, L., \& Egeland, B. (1985). The relationship between quality of attachment and behavior problems in preschool in a high-risk sample. In I. Bretherton \& E. Waters (Eds.), Growing points of attachment theory and research. Monographs of the Society for Research in Child Development, 50(1-2, Serial No. 209), 147-166.

Feeney, J.A. \& Noller, P. (1990). Attachment style as a predictor of adult romantic relationships. Journal of Personality and Social Psychology, 58(2), 281-291. Feeney, J.A. \& Noller, P. (1996). Adult attachment. London: Sage Publications. Flanagan, T.J. (1981). Dealing with long-term confinement: Adaptative strategies and perspective among long-term prisoners. Criminal Justice and Behavior, 8(2), 201222.

Flanagan, T.J. (1983). Correlates of institutional misconduct among state prisoners. Criminology, 21(1), 29-39.

George, C., Kaplan, N., \& Main, M. (1985). The attachment interview for adults. Unpublished manuscript, University of California, Berkeley.

Glick, I.O., Weiss, R.J., \& Parkes, C.M. (1974). The first year of bereavement. New York: John Wiley \& Sons.

Gray, C., Koopman, E., \& Hunt, J. (1991). The emotional phases of marital separation: An empirical investigation. American Journal of Orthopsychiatry, 61(1), 138- 
143.

Green, S.B., Salkind, N.J., \& Akey, T.M. (1997). Using SPSS for windows: Analyzing and understanding data. Upper Saddle River, New Jersey: Prentice-Hall.

Griffin, D., \& Bartholomew, K. (1994). Models of the self and other: Fundamental dimensions underlying measures of adult attachment. Journal of Personality and Social Psychology, 67(3), 430-445.

Grossmann, K.E., \& Grossmann, K. (1991). Attachment quality as an organizer of emotional and behavioral responses in a longitudinal perspective. In C.M. Parkes, J. Stevenson-Hinde, \& D. Marris (Eds.), Attachment across the life cycle (pp. 93-114). London: Tavistock/Routledge.

Hairston, C.F. (1987). Family ties during imprisonment: Important to whom and important for what? Journal of Sociology and Social Welfare, 20, 87-104. Hammond, J.R., \& Fletcher, G.. (1991). Attachment styles and relationship satisfaction in the development of close relationships. New Zealand Journal of Psychology, 20, $56-62$.

Harris, J.W. (1993). Comparison of stressors among female versus male inmates. Journal of Offender Rehabilitation, 19(1/2), 43-56.

Hazan, C., \& Shaver, P.R. (1987). Romantic love conceptualized as an attachment process. Journal of Personality and Social Psychology, 52, 511-524.

Hazan, C. \& Shaver, P.R. (1994). Attachment as an organizational framework for research on close relationships. Psychological Inquiry, 5, 1-22.

Horowitz, L.M. (1996). The study of interpersonal problems: A Leary legacy. Journal of 
Personality Assessment, 66(2), 283-300.

Horowitz, L.M., Rosenberg, S.E., \& Bartholomew, K. (1993). Interpersonal problems, attachment styles, and outcome in brief dynamic psychotherapy. Journal of Consulting and Clinical Psychology, 61(4), 549-560.

Ivanhoff, A. (1992). Background risk factors associated with parasuicide among male prison inmates. Criminal Justice and Behavior, 19(4), 426-436.

Jorgenson, J.F., Hernandez, S.H., \& Warren, R.C. (1986). Addressing the social needs of families of prisoners: A tool for inmate rehabilitation. Federal Probation, 50, 47-52.

Kemp, G., Glaser, B., Page, R., \& Horne, A. (1992). Influence of family support on men in a minimum security detention center. Journal of Addictions and Offender Counseling, 12, 34-46.

Kenny, M.E. (1987). The extent and function of parental attachment among first-year college students. Journal of Youth and Adolescence, 16(1), 17-29.

Kenny, M.E. \& Rice, K.G. (1995). Attachment to parents and adjustment in late adolescent college students: Current status, applications, and future considerations. The Counseling Psychologist, 23(3), 433-456.

King, A. (1993). Helping inmates cope with family separations and role strain: A group work approach. Social Work With Groups, 16(4), 43-55.

Kirkpatrick, L.A., \& Davis, K.E. (1994). Attachment style, gender, and relationship stability: A longitudinal analysis. Journal of Personality and Social Psychology, $66(3), 502-512$. 
Kobak, R.R., \& Sceery, A. (1988). Attachment in late adolescence: Working models, affect regulation, and representation of self and others. Child Development, 59, 135-146.

Koenig, C. (1985). Life on the outside. Chilliwack: Chilliwack Community Services. Kramer, J.J., \& Conoley, J.C. (1992). The eleventh mental measurements yearbook. Lincoln, Nebraska: The University of Nebraska Press.

Levy, M.B. \& Davis, K.E. (1988). Lovestyles and attachment styles compared: Their relations to each other and to various relationship characteristics. Journal of Social and Personal Relationships, 5, 439-471.

Lewis, M., Feiring, C., McGuffog, C., \& Jaskir, J. (1984). Predicting psychopathology in the six-year olds from early social relations. Child Development, 55, 123-136.

Londerville, S. \& Main, M. (1981). Security of attachment, compliance, and maternal training methods in the second year of life. Developmental Psychology, 17, 289-299.

Lopez, F.G. (1995). Contemporary attachment theory: An introduction with implications for counseling psychology. The Counseling Psychologist, 23(3), 395-415.

Lyddon, W.J., Bradford, E., \& Nelson, J.P. (1993). Assessing adolescent and adult attachment: A review of current self-report measures. Journal of Counseling and Development, 71, 390-395. 
MacKenzie, D.L., Shaw, J.W., \& Souryal, C. (1992). Characteristics associated with successful adjustment to supervision: A comparison of parolees, probationers, and shock participants, and shock dropouts. Criminal Justice and Behavior, 19(4), $437-454$.

MacKenzie, D. \& Goodstein, L. (1985). Long-term incarceration impacts and characteristics of long-term offenders: An empirical analysis. Criminal Justice and Behavior, 12, 395-414.

Main, M., Kaplan, N., \& Cassidy, J. (1985). Security in infancy, childhood, and adulthood: A move to the level of representation. In I. Bretherton \& E. Waters (Eds.), Growing points of attachment theory and research. Monographs of the Society for Research in Child Development, 50 (1-2, Series No. 209), 66-104.

Main, M. \& Goldwyn, R. (1985). Adult attachment classification system. Unpublished manuscript, University of California, Berkeley.

Marshall, W.L. (1993). The role of attachment, intimacy, and loneliness in the etiology and maintenance of sexual offending. Sexual and Marital Therapy, 8, 109-121. Marshall, W.L. \& Mazzuco, A. (1995). Self-esteem and parental attachments in child molesters. Sexual Abuse: A Journal of Research and Treatment, 7(4), 279-285. Marshall, W.L. (1989). Invited essay: Intimacy, loneliness, and sexual offenders. Behavior Research and Therapy, 27, 491-503.

Mayseless, O., Danieli, R., \& Sharabany, R. (1996). Adults' attachment patterns: Coping with separations. Journal of Youth and Adolescence, 25(5), 667-690. 
McShane, M. \& Williams, F.P. (1989). The prison adjustment of juvenile offenders. Crime and Delinquency, 35(2), 254-269.

Medway, F.J., Davis, K.E., Cafferty, T.P., Chappell, K.D., \& O'Hearn, R.E. (1995). Family disruption and adult attachment correlates of spouse and child reactions to separations and reunion due to Operation Desert Storm. Journal of Social and Clinical Psychology, 14(2), 97-118.

Megargee, E. \& Bohn, M. (1977). A new classification system for criminal offenders, IV: Empirically determined characteristics of the ten types. Criminal Justice and Behavior, 4, 149-210.

Mikulincer, M., \& Florian, V., \& Tolmatz, R. (1990). Attachment styles and fear of personal death: A case study of affect regulation. Journal of Personality Social Psychology, 58, 273-280.

Mikulincer, M. \& Nachson, O. (1991). Attachment styles and patterns of self-disclosure. Journal of Personality and Social Psychology, 61(2), 321-331.

Mikulincer, M., \& Avev, I. (1991). Attachment style and the structure of romantic love. British Journal of Social Psychology, 30, 273-291.

Mikulincer, M., Florian, V., \& Weller, A. (1993). Attachment styles, coping strategies, and posttraumatic psychological distress: The impact of the Gulf War in Israel. Journal of Personality and Social Psychology, 64(5), 817-826. 
Mikulincer, M., \& Florian, V. (1995). Appraisal of and coping with a real-life stressful situation: The contribution of attachment styles. Personality and Social Psychology Bulletin, 21(4), 406-414.

Myers, L. \& Levy, G. (1978). Description and prediction of the intractable inmate. Journal of Research in Crime and Delinquency, 15, 214-228.

Parkes, C.M. (1987). Bereavement: Studies of grief in adult life. London: Tavistock. Parkes, C.M. (1973). Separation anxiety: An aspect of the search for a lost object. In R.S. Weiss (Ed.), Loneliness: The experience of emotional and social isolation. Cambridge, MA: MTT Press.

Petersilia, J. \& Honig, P. (1980). The prison experience of career criminals. $\underline{\text { Rand }}$ Report Series, R-2511-DOJ, Santa Monica, CA: Rand Corporation.

Piersma, H.L., Reaume, W.M., \& Boes, J.L. (1994). The Brief Symptom Inventory (BSI) as an outcome measure for adult psychiatric patients. Journal of Clinical Psychology, 50(4), 555-563.

Piersma, H.L., Boes, J.L., \& Reaume, W.M. (1994). Unidimensionality of the Brief Symptom Inventory (BSI) in adult and adolescent inpatients. Journal of Personality Assessment, 63(2), 338-344.

Pistole, M.C. (1995). College students' ended love relationships: Attachment style and emotion. Journal of College Development, 36(1), 53-60.

Pistole, M.C. (1994). Closeness-distance struggles. Family Processes, 33, 147-159. Pistole, M.C. (1989). Attachment in adult romantic relationships: Style of conflict resolution and relationship satisfaction. Journal of Social and Personal 
Relationships, 6, 505-510.

Pistole, M.C. \& Tarrant, N. (1993). Attachment style and aggression in male batterers. Family Therapy, 20(3), 165-173.

Power, K, \& Beveridge, L. (1990). The effects of custody in a Scottish detention centre on inmates self-esteem. International Journal of Offender Therapy and Comparative Criminology, 32, 177-186.

Priel, B. \& Shamai, D. (1995). Attachment style and perceived social support: Effects on affect regulation. Personality and Individual Differences, 19(2), 235-241.

Pugh, D. (1993). The effects of problem-solving ability and locus of control of prisoner adjustment. International Journal of Offender Therapy and Comparative Criminology, 37(2), 163-176.

Putnam, S.H., Kurtz, J.E., \& Houts, D.C. (1996). Four-month test-retest reliability of the MMPI-2 with normal male clergy. Journal of Personality Assessment, 67(2), 341353.

Quereshi, M.Y. \& Kleman, R. (1996). Validation of selected MMPI-2 basic and content scales. Current Psychology-Developmental, Learning, Personality, Social, 15(3), 249-253.

Radecki-Bush, C, Farrell, A.D., \& Bush, J.P. (1993). Predicting jealous responses: The influence of adult attachment and depression on threat appraisal. Journal of Social and Personal Relationships, 10, 569-588.

Rice, K.G., FitzGerald, D.P., Whaley, T.J., \& Gibbs, C.L. (1995). Cross-sectional and longitudinal examination of attachment, separation-individuation, and college 
student adjustment. Journal of Counseling and Development, 73, 463-474.

Richards, B. (1978). The experience of long-term imprisonment. British Journal of Criminology, 10(2), 162-169.

Schmid, T.J. \& Jones, R.J. (1993). Ambivalent actions: Prison adaptation strategies of first-time, short-term inmates. Journal of Contemporary Ethnography, 21(4), 439463.

Schneller, D.P. (1976). The prisoner's family: A study of the effects of imprisonment or the families of prisoners. San Francisco: R \& E Research Associates.

Senchak, M. \& Leonard, K.E. (1992). Attachment styles and marital adjustment among newlywed couples. Journal of Social and Personal Relationships, 9, 51-64.

Shaver, P.R., \& Brennan, K.A. (1992). Attachment styles and the "Big Five" personality traits: Their connections with each other and with romantic relationship outcomes. Personality and Social Psychology Bulletin, 18(5), 536-545.

Shaver, P.R. \& Hazan, C. (1993). Adult romantic attachment: Theory and evidence. In D. Perlman \& W. Jones (Eds.), Advances in Personal Relationships (Vol. 4, pp. 29-70). London: Jessica Kingsley.

Shaver, P.R. \& Hazan, C. (1988). A biased overview of the study of love. Journal of Social and Personal Relationships, 5, 473-501.

Shaver, P.R., Hazan, C., \& Bradshaw, D. (1988). Love as attachment: The integration of three behavioral systems. In R.J. Sternberg \& M. Barnes (Eds.), The psychology of love (pp. 68-99). New Haven, CT: Yale University Press.

Siegert, R.J., Ward, T., \& Hudson, S. (1995). The structure of romance: A factor- 
analytic examination of the relationship scales questionnaire. New Zealand Journal of Psychology, 24(1), 13-20.

Silverman, M. \& Vega, M. (1990). Reactions of prisoners to stress as a function of personality and demographic variables. International Journal of Offender Therapy and Comparative Criminology, 32, 187-196.

Simpson, J.A. (1990). Influence of attachment styles on romantic relationships. Journal of Personality and Social Psychology, 59(5), 971-980.

Simpson, J.A., Rholes, W.S., \& Nelligan, J.S. (1992). Support seeking and support giving within couples in an anxiety provoking situation: The role of attachment styles. Journal of Personality and Social Psychology, 62(3), 434-446.

Smyth, N. \& Ivanhoff, A. (1994). Maladaptation and prison environmental preferences among inmate parasuicides. Journal of Offender Rehabilitation, 20(3/4), 131-146.

Smyth, N., Ivanhoff, A., \& Jang, S.J. (1994). Changes in psychological maladaptation among prison inmate parasuicides. Criminal Justice and Behavior, 21(3), 357365.

Sperling, M.B., \& Berman, W.H. (1991). An attachment classification of desperate love. Journal of Personality Assessment, 56(1), 45-55.

Spiro, A., Butcher, J.N., Levenson, M.R., Aldwin, C.M., \& Bosse, R. (1993). Personality change and stability over five years: The MMPI- 2 in older men. Paper presented at the meeting of the American Psychological Association, Toronto, Canada.

Sroufe, L.A., Egeland, B., \& Kreutzer, T. (1990). The rate of early experiences following developmental change: Longitudinal approaches to individual adaptation in 
childhood. Child Development, 61, 1363-1373.

Strassberg, D.S. (1997). A cross-national study of four MMPI-2 content scales. Journal of Personality Assessment, 69(3), 596-606.

Thomas, C.W. (1977). Theoretical perspectives on prisonization: A comparison of the importation and deprivation models. Journal of Criminal Law and Criminology, 68(1), 135-145.

Thomas, C.W. (1975). Prisonization or resocialization?: A study of external factors associated with the impact of imprisonment. Journal of Research in Crime and Delinquency, 13-21.

Thompson, B. (2002). "Statistical," "practical," and "clinical": How many kinds of significance do counselors need to consider? Journal of Counseling and Development, 80, 64-71.

Toch, H., Adams, K., \& Grant, J.D. (1989). Coping: Maladaptation in prisons. New Brunswick, NJ: Transaction Books.

Toch, H., Adams, K., \& Greene, R. (1987). Ethnicity, disruptiveness, and emotional disorders among prison inmates. Criminal Justice and Behavior, 14, 93-109.

Toch, H. \& Adams, K. (1986). Pathology and disruptiveness among prison inmates. Journal of Research in Crime and Delinquency, 23, 7-21.

Vormbrock, R.S. (1993). Attachment theory as applied to wartime and job-related marital separation. Psychological Bulletin, 114(1), 122-144.

Walters, G. (1991). Predicting the disciplinary adjustment of maximum and minimum security prison inmates using Lifestyle Criminality Screening Form. International 
Journal of Offender Therapy and Comparative Criminology, 35(1), 63-71.

Ward, C.L. (1997). Confirmatory factor analyses of the anxiety and depression content scales. Joumal of Personality Assessment, 68(3), 678-691.

Ward, T., Hudson, S., \& Marshall, W. (1996). Attachment style in sex offenders: A preliminary study. The Journal of Sex Research, 33(1), 17-26.

Ward, T., Hudson, J.M., Marshall, W.L., \& Siegert, R. (1995). Attachment style and intimacy deficits in sex offenders: A theoretical framework. Sexual Abuse: A Journal of Research and Treatment, 7(4), 317-355.

Waters, E., Wippman, J., \& Sroufe, L.A. (1979). Attachment, positive affect, and competence in the peer group: Two studies in construct validation. Child Development, 50, 821-829.

Weiss, R.S. (1991). The attachment bond in childhood and adulthood. In C.M. Parkes, S. Stevenson-Hinde, \& P. Marris (Eds.), Attachment across the life cycle (pp. 6676). London: Tavistock/Routledge.

Weiss, R.S. (1982). Attachment in adult life. In C.M. Parkes \& J. Stevenson-Hinde (Eds.), The place of attachment in human behavior (pp. 171-184). New York: Basic Books.

Weiss, R.S. (1975). Marital separation. New York: Basic Books.

West, M.L. \& Sheldon-Keller, A.E. (1994). Patterns of relating: An adult attachment perspective. New York: Guilford Press.

Williams, D., \& Schill, T. (1994). Adult attachment, love styles, and self-defeating personality characteristics. Psychological Reports, 75, 31-34. 
Wright, K.N. (1989). Race and economic marginality in explaining prison adjustment. Journal of Research in Crime and Delinquency, 26(1), 67-89.

Zamble, E. (1992). Behavior and adaptation in long-term prison inmates: Descriptive longitudinal results. Criminal Justice and Behavior, 19(4), 409-425.

Zamble, E. \& Porpino, F.J. (1990). Coping, imprisonment, and rehabilitation: Some Data and their implications. Criminal Justice and Behavior, 17, 53-70.

Zamble, E. \& Porpino, F.J. (1988). Coping, behavior, and adaptation in prison inmates. New York: Springer-Verlag.

Zuroff, D.C., \& Fitzpatrick, D.K. (1995). Depressive personality styles: Implications for adult attachment. Personality and Individual Differences, 18(2), 253-265. 